\title{
Bond behaviour between early age concrete and steel bar subjected to cyclic loading after fire
}

\author{
Limin $\mathrm{Lu}^{1,2}$, Guanglin Yuan ${ }^{1,2}$, Qianjin Shu ${ }^{1,2}$, Zhaohui Huang ${ }^{3,{ }^{*}}$, Chongshuo Zhong ${ }^{2}$, Bin Xu ${ }^{2}$ \\ ${ }^{1}$ State Key Laboratory for Geomechanics \& Deep Underground Engineering, China University of Mining \\ \& Technology, Xuzhou, Jiangsu 221116, China \\ ${ }^{2}$ School of Mechanics and Civil Engineering, China University of Mining and Technology, Xuzhou, \\ 221116, China \\ ${ }^{3}$ Department of Civil and Environmental Engineering, Brunel University London, Uxbridge, \\ Middlesex, UB8 3PH, UK.
}

\begin{abstract}
:
This paper presents a comprehensive experimental study to investigate the bond behaviour between early age concrete and steel bar subjected to cyclic loading after fire. In this research, three temperatures of $150{ }^{\circ} \mathrm{C}, 350{ }^{\circ} \mathrm{C}, 550{ }^{\circ} \mathrm{C}$ and four curing ages of $3,7,14,28$ days were used. The effect of cooling methods on the bond behaviour has been evaluated. The influence of transverse stirrup on the bond characteristics has also been investigated. A total of 32 groups of specimens have been tested. In order to generate reliable test data, three identical specimens were tested for each group and average values were calculated. The research has generated a set of valuable test data for the fellow researchers who develop numerical models and practical structural engineers who evaluate the seismic performance and fire resistance of reinforced concrete structures after a fire happened during the construction stage.
\end{abstract}

Keywords: Cyclic loading; early age concrete; bond behaviour; fire; reinforced concrete member

* Corresponding author, E-mail address: zhaohui.huang@brunel.ac.uk (Z. Huang) 


\section{RESEARCH HIGHLIGHTS:}

$>$ Investigate the influence of different temperatures on the degradation of the bond strength.

Study the bond behaviours of the early age concrete with different curing ages.

$>$ Investigate the impact of different cooling methods on the residual bond strength.

$>$ Understand the influence of stirrup on the residual bond strength after fire. 


\section{Introduction}

Fire is one of major disasters for concrete structure. In recent years a large number of reinforced concrete buildings are under construction in some developing countries, such as China. However, due to the problem of construction procedure and management on the construction site, fires could happen during the construction stage of buildings. For example, in 2009 a new Chinese CCTV cultural centre building was on a big fire during its construction period which had the fire area of $8000 \mathrm{~m}^{2}$. The fire caused considerable damages to the building. As another example, a big fire lasted for 4.5 hours happened at the 23 floor on the 25 storeys reinforced concrete building which was just finished concreting for 3 days in Wuhan, China [1]. The temperature within the concrete floor reached $400{ }^{\circ} \mathrm{C}$. The concrete strength was significantly affected by the fire. Therefore, if a fire incident occurs during construction period it is important for structural engineers to assess the residual strengths of the younger RC structural members for the evaluation of the safety and reparability of that building after a fire. For RC structures, one of important issues is to understand the impact of fire on the residual strength of bond between early age concretes and reinforcing steel bars which is a key factor to influence residual load capacity of a RC structural member after a fire.

At present, there are considerable numbers of studies on the bond behaviour of RC members at both ambient and elevated temperatures have been conducted, in with the concrete age is normally more than 28 days [2-5]. Wu and Chen [3] developed two distinct groups of bond models at ambient temperature which were based on the basis of dominant concrete splitting and rebar-concrete interfacial failures, respectively. El-Hawary and Hamoush [6] used the pull-out test results together with analytical model to calculate the bond shear modulus, and the influence of high temperature on it. Bingöl and Gül [7] found that the residual bond strength of reinforced concrete members after exposed to high temperature increases with the increasing of the anchorage length of steel bars and concrete compressive strength. Arel [8] carried out a series of pull-out tests under different temperatures and the results indicated that with the increase of concrete cover thickness the influence of high temperature on the bond strength of reinforced concrete was reduced. Ergun et al. [9] conducted pull-out tests on the cylinder specimens, the results indicated that the residual bond strength of the specimens after exposed to high temperature was not directly depended on the strength of concrete only. With the increase of steel bar diameter, the residual bond strength of the specimens decreased. 
Haddad and Shannis [10], studied the bond behaviour between high strength ash concrete and reinforcing steel bar after fire. The research indicated that the residual bond strengths of the specimens exposed to the temperatures of 600 and $800{ }^{\circ} \mathrm{C}$ were reduced by $24 \%$ and $74 \%$, respectively. Yang et al. [11] found that the bond strength and slip at bond failure of the specimens with stirrup were bigger than the one of the specimens without stirrups. However, the differences between the two specimen types were decreasing with increasing temperature.

Huang [12] developed a finite element model to simulate the bond characteristics of reinforced concrete members under fire conditions. The research pointed out that the bond condition of a reinforced concrete member has important effects on the fire resistance of that member and the assumption of perfect bounding between concrete and reinforcing steel bar is unsafe for evaluating fire resistance of reinforced concrete structures. A robust numerical model developed by Khalaf et al. [13] takes into account the influences of concrete cover, material properties, rebar shape and diameter and some other factors on the bond behaviour at elevated temperatures. Pothisiri and Panedpojaman [14] also developed a high temperature bond model based on the theory of coating cracks. The model can establish the relationship between the bond strength and fracture radius. Kodur and Agrawal [15] used a finite element model to investigate the impact of bond-slip relationship on the fire resistance of reinforced concrete beams. The study has shown that under high temperature the bond-slip between steel bar and concrete can considerably affect the fire resistance of reinforced concrete beams.

All studies mentioned above focused on the bond characteristics between steel rebar and concrete with curing age more than 28 days. As mentioned before, due to the problem of construction procedure and management on construction sites, fires could happen during the construction stage of buildings. Hence, the research presented in this paper is focused on the residue bearing performance of the cast-in-situ concrete structure after a fire during the construction phase. In the construction stage the concrete is still in its very early age. Hence, the bond behaviour between early age concrete and steel rebar is considerably different compared to normal concrete with the curing age more than 28 days. Therefore, in this research the concrete ages of 3, 7, 14 and 28 days are selected. It is well known that the water content of early age concrete is high. The water content has significant impacts on the hydration of cement within concrete. The water within the concrete will influence the concrete strength's recover after a fire. In this research there is no measurement on the water contents for different ages of concrete. However, this will be reflected in the different standing ages of the specimens after fire. 
Recently, Li et al. [16] conducted a series pull-out tests on the bond behaviour between early aged fly ash concrete and reinforcing steel bar exposed to high temperature. The research indicated that the curing ages of fly ash concrete has considerable influences on the residual bond strength. However, compared with normal curing age (28 day or more) concrete, there are still very limited studies on the bond characteristics of early age concrete at elevated temperatures. For all previous studies mentioned above, the post-fire bond properties were investigated through pseudo-static pullout testing. Hence, it is difficult to use those date to evaluate the seismic performance of the buildings after a fire during construction period. According to the authors' knowledge there are no any tested data available for the bond behaviour between early age concrete and steel rebar under cyclic loading condition in fire. Those data are very important for structural engineers to assess the residual strength of the buildings, especially for evaluation of the seismic resistance of the buildings and determination of repair plan.

Therefore, the main objectives of this research are:

- Conduct a series of tests to investigate the residual bond strength between early age normal strength concrete and steel rib bar subjected to cyclic loading condition and under different temperatures, and cooling methods.

- Study the influence of temperatures $\left(150{ }^{\circ} \mathrm{C}, 350{ }^{\circ} \mathrm{C}, 550{ }^{\circ} \mathrm{C}\right)$ on the degradation of the bond strength and bond stress-slip relationships.

- Investigate the bond characteristics of concrete with different curing ages $(3,7$, 14,28 days).

- Understand the impact of different cooling methods (natural air cooling, water spray cooling) on the bond characteristics.

- Generate a set of valuable test data for the fellow researchers who develop numerical models and practical structural engineers who evaluate the seismic performance and fire resistance of the reinforced concrete buildings after a fire during construction stage.

\section{Specimens' design}

In this research the specimens were made of C30 normal strength concrete. The P.O42.5 composite Portland cement, produced by Xuzhou Zhonglian Cement Company, was used. The flexural strength of the concrete tested on the $3 \mathrm{rd}$ and 28 th day is $5.5 \mathrm{MPa}$ and $8.8 \mathrm{MPa}$, 
respectively. The compressive strength of the cement tested on the 3rd and 28th day is 31.2MPa and 49.6MPa, respectively. The fine aggregate used was medium sand and coarse aggregate was continuous grading macadam with 5 to $16 \mathrm{~mm}$ in diameter. Table 1 gives the composition of the concrete. Table 2 shows the chemical composition of cement. Table 3 lists the particle size distribution of coarse aggregate and fine aggregate. Main reinforcing rib bar was HRB400 grade of $16 \mathrm{~mm}$ diameter steel bar. The stirrup used was $6 \mathrm{~mm}$ diameter HPB300 grade steel. Table 4 presents detailed characteristics and mechanical properties of steel rib bar and stirrup.

The details of the specimens used in this research are shown in Fig. 1. The size of the specimen is $160 \mathrm{~mm} \times 150 \mathrm{~mm} \times 150 \mathrm{~mm}$ with one steel rib bar which has the diameter of $16 \mathrm{~mm}$. For the specimens with stirrup, the stirrup was placed at the middle of bond section with the concrete cover of $25 \mathrm{~mm}$. According to the Chinese code [17], for a pull-out test the embed length of steel bar should not be less than five times of the bar diameter. Based on the test results [18], when the relative bond length increases the distribution of bond-stress along the bond length tends to be non-uniform and also the average bond strength reduces. Hence, in this study the bond length of $100 \mathrm{~mm}$ was adopted. In order to avoid local compression of concrete and large difference of stresses near the end of steel bar, at both end of the embed length, $30 \mathrm{~mm}$ PVC tubes were used to sleeve the outside of rib bar in order to form unbonded areas (see Fig. 1).

The existing literatures show that at ambient temperature the bond strength of reinforced concrete at early age, especially with the curing age of 7 to 14 days, decreases with increasing curing age [19]. Tang et al. [20] pointed out that the strength of concrete increases quickly before the curing age of 3 days. The concrete with 3 days curing age can reach considerable strength, hence, in this study four curing ages of 3, 7, 14 and 28 days were adopted.

For fire resistance requirement of reinforced concrete members, the normal concrete cover to the reinforcing steel is more than $25 \mathrm{~mm}$. Due to the poor thermal conductivity of concrete the maximum temperature of reinforcing steel bars during fire is normally less than $600{ }^{\circ} \mathrm{C}$ [13]. Previous research [21] indicated that the bond strength of reinforced concrete can be reduced up to $60 \%$ after exposed to high temperature (over $500{ }^{\circ} \mathrm{C}$ ). At such high temperature level, the residual compressive strength and bond strength of concrete drops sharply and the structures cannot be meaningfully repaired or strengthened. Hence, three temperatures of 150 ${ }^{\circ} \mathrm{C}, 350{ }^{\circ} \mathrm{C}, 550{ }^{\circ} \mathrm{C}$ were selected in this study. Also for considering real building fire and firefighting, natural air cooling (air cooling) and water spray cooling (water cooling) were 
used. For assessing the influence of stirrup on the bond strength of reinforced concrete member some specimens were reinforced with stirrup (see Fig. 1).

As shown in Table 5, a total 32 groups of specimens were used which included 2 groups of specimens tested at ambient temperature for comparison. In Table 5, Group number gives the information of specimens which includes curing age, heated temperature, cooling method and with or without stirrup. For example, group number F3d150Z-H: 3d = 3 days curing age, 150 $=150{ }^{\circ} \mathrm{C}, \mathrm{Z}=$ natural air cooling, $\mathrm{H}=$ with stirrup; group number F14d350S: $14 \mathrm{~d}=14$ days curing age, $350=350{ }^{\circ} \mathrm{C}, \mathrm{S}=$ water cooling, without stirrup. For generating reliable test data, three identical specimens were tested for each group and the average values were calculated, hence a total of 96 specimens were tested in this research.

\section{Test programme}

Specimens were made using wood pattern. After demoulding, all specimens were stored in water (at temperature of $20 \pm 3{ }^{\circ} \mathrm{C}$ ) in the structural lab's curing room for a period of designed curing ages, such as, 3, 7, 14 and 28 days. Then the specimens were heated to the design temperatures without loading. In this study, an electrical heating furnace with power of $18 \mathrm{~kW}$ was used. The maximum heating temperature of $1100{ }^{\circ} \mathrm{C}$ can be achieved. The furnace has computerized temperature control system. For simulating real fire, high heating ratio was adopted. Based on the recommendation from previous research [16, 22], a high heating rate of $10{ }^{\circ} \mathrm{C} / \mathrm{min}$ was used for all tests. In order to achieve uniform temperature distribution within the specimens, the specimens were heated to the target temperatures $\left(150^{\circ} \mathrm{C}, 350{ }^{\circ} \mathrm{C}, 550{ }^{\circ} \mathrm{C}\right)$ then the target temperatures were maintained for $90 \mathrm{~min}$ before cooled down to ambient temperature. Table 6 gives the heating and maintaining times for three temperature levels.

As mentioned in the introduction section, if a fire incident occurs during construction period it is important for structural engineers to assess the residual strengths of the younger $\mathrm{RC}$ structural members for the evaluation of the safety and reparability of that building after a fire. Previous research [16] indicated that the bond strength between concrete and reinforcing steel bar can be recovered after cooling down to ambient temperature. The degree of recovery is depended on the curing age of concrete and the standing time after cooling. Therefore in this research after the specimens were cooled down to ambient temperature, the specimens were kept in the normal labs' environment until a total of 28 days (curing age + standing age) was reached. Then the pull-out tests were conducted. In addition, the compressive strength of concrete tested immediately after cooling are listed in Table 7, and the compressive strengths 
and splitting strengths of the concrete exposed the same way as the pullout specimens are listed in Table 8.

After exposed to fire, the mechanical properties of concrete material and the bonding strength between concrete steel are considerably degraded. In theory, concrete and bonding strengths can get a certain amount of recovery after fire. This is due to continuing hydration of cement in concrete. The strength recovery is dependent on the different recovering ages. However, in this research the one of the main objectives is to generate some valuable data for structural engineers to assess the residual strength of the buildings immediately after fire and determinate repair plan for continuing construction of the building. Therefore a total of 28 days (curing age + standing age) was adopted in this research. For the further study it is useful to use different standing ages to evaluate the influences of this factor on the long-term bond properties.

As shown in Fig. 2, a PWS500 type electro-hydraulic servo testing machine was used for conducting the tests. As shown in the figure, two displacement gauges were installed at the two ends of the steel bar for measuring the slip between steel bar and reinforced concrete. In this measurement arrangement it is assumed that the deformation of concrete block is relatively small and can be ignored. Hence, the differences between the displacements of concrete block and the ends of steel rebar are reasonably approximated as the bond slips. This measurement method has been adopted by many other researchers. The cycling loading set-up is shown in Fig. 3.

For better understanding the behaviour of bond, from elastic stage to elastic and plastic stage to failure stage, in this study a "load - displacement hybrid control loading system" was adopted. Based on the failure loads of previous monotonic pull-out tests, the failure cyclic load was estimated for each specimen and corrected with the computer data acquisition system. As shown in Fig. 4, at the beginning of the test, the load control was used. For the first cycle, the positive axial force was linearly increased from 0 to $1 \mathrm{kN}$, then linearly unloaded to 0 . After that, a negative axial force was linearly applied from 0 to $-1 \mathrm{kN}$ and then unloaded to 0 . For next loading cycle, the maximum load was increased by $1 \mathrm{kN}$ and the loading procedure was repeated until the load cannot be further increased. At this point, the specimen reached the stage of damage then the displacement control was activated. For displacement control stage, the loading speed was set to be $0.5 \mathrm{~mm} / \mathrm{min}$. The maximum displacement was increased by $1 \mathrm{~mm}$ for each cycle until the specimen was totally failure then the test was stopped (see Fig. 4). 
In this research a DH3818 high-speed synchronous data acquisition system was used to collect the data of slips and pull-out forces. Two YHD-50 displacement meters were used to measure the actual displacements between the steel frame and ends of steel bar (see Fig. 3). Loads on the steel bars were obtained by sensors attached to the servo testing machine.

\section{Results and discussions}

The bond stress between concrete and steel bar can be calculated as:

$$
\tau=\frac{F}{\pi d l}
$$

where:

$$
\begin{gathered}
\tau=\text { bond stress }(\mathrm{MPa}) \\
F=\text { Pull-out force }(\mathrm{N}), \\
d=\text { diameter of steel } \operatorname{bar}(\mathrm{mm}), \\
\quad l=\text { bond length }(\mathrm{mm})
\end{gathered}
$$

As mentioned before there were three specimens for each test group. Hence, the test results were the average values of three specimens tested. Using calculated bond stress $\tau$ and measured bond slip $S$, the bond's stress-slip $(\tau-S)$ curve can be generated for each specimen group.

For analysis of bond strength, it is well known that the pull-out force is resisted by the mechanical action between the steel rebar's ribs and the surrounding concretes. The transfer of the load between the reinforced bar and concrete is achieved by the bearing of the ribs on the concrete. The resultant forces acting on the ribs are compressive forces which are generated due to the restraint of the surrounding concrete. The compressive forces acting on the ribs resulted from the pull out load are decomposed into two directions, parallel and perpendicular to the reinforced steel bar. The reaction forces acting on the concrete, due to the perpendicular components of the compressive forces acting on the ribs, create circumferential tension stresses in the concretes surrounding the steel bar. If these tensile stresses exceed the tensile strength of concrete, splitting failure occurs [13]. Hence, bond strength is mainly depended on the tensile strength of the concrete around the interface. As shown on Table 8 the concrete tensile strength of the specimens is about $8-10 \%$ of their compressive strength. This ratio is similar to the concrete at ambient temperature. Therefore the model developed by 
Khalaf et al. [13], which is mainly based on the partly cracked thick-wall cylinder theory for analysing bond strength of normal reinforced concrete member at elevated temperatures, may be suitable for the early age concrete members after fire.

Table 9 gives the ultimate bond stress $\tau_{\max }$ and the ultimate bond slip $S_{\max }$ (which is the bond slip corresponding to the ultimate bond stress $\tau_{\max }$ ) for all specimen's groups. $\tau_{\max }$ is calculated using Eqn. (1). Hence, $\tau_{\max }$ is the bond strength and is not the shear strength at the surface of the deformed bars.

In 1982 Ciampi et al. [23] developed an analytical model for predicting the behaviour of single deformed reinforcing bars embedded in confined concrete and subjected to generalized excitations in the range of low cycle fatigue. The model could be further extended to relate the temperature effect on the residual bond strength between concrete and reinforcing steel bar after exposed to fire. Also the model can help to explain the experimental data more clearly.

\subsection{Characteristics of the hysteresis and envelope curves of specimens}

\subsubsection{The hysteresis curves of specimens}

It is well known that hysteresis curve can be used to comprehensively describe the elasticplastic properties and seismic performance of the specimens. The change of ring shape of a hysteresis curve in different stages reflects the deformation mechanism of the specimens. Due to the similarity of the hysteresis curves of specimens, in this section a typical hysteretic bond-slip curve of specimen group F28d350S-H (shown in Fig. 5) is discussed in details. The specimens were with stirrup and had the curing age of 28 days, exposed to $350{ }^{\circ} \mathrm{C}$ high temperature and cooled by water cooling.

As shown in Fig.5, it can be seen that under low cycle reciprocating load, the bond-slip curve of the specimen can be divided into the elastic stage, elastic-plastic stage and failure stage. In the elastic stage, the bond between steel bar and concrete was very strong and the hysteresis loop was in spindle "tip" shape (see Fig. 6(a)). The stiffness of the specimen was basically unchanged. The area enclosed by the hysteresis loop is smaller, hence, the energy dissipation capacity of the specimen is smaller. In elastic-plastic stage, due to some damages happened on the interface between steel bar and concrete, the area of the hysteresis loop was increased and "rheostriction effect" was appeared. The hysteresis loop was in "flat Z" shape (see Fig. 6(b)). At this stage, when the specimen was unloaded to zero, the specimen had considerable residual deformation which should not be neglected. The specimen had certain ability of 
energy consumption. In the failure stage, with the increase of load the bond stress decreased, and the "rheostriction effect" on the hysteresis loop became more apparent. The residual deformation of the specimen increased gradually and the hysteresis loop was in " $Z$ " shape (see Fig. 6(c)).

\subsubsection{The envelope curves of specimens}

Fig. 7 shows the envelope curves for all specimen's groups. The ultimate bond stress $\tau_{\max }$ and the ultimate bond slip $\mathrm{S}_{\max }$ (which is the bond slip corresponding to the ultimate bond stress $\left.\tau_{\max }\right)$ for all specimen's groups are presented in Table 9. Also, the ratios between the pullout strength and the compressive strength are listed in Table 9. Due to the symmetry of envelope curve, Table 5 only gives positive $\tau_{\max }$ and $\mathrm{S}_{\max }$ for each specimen group. From Fig. 7 it can be seen that loading and unloading stiffness of the envelope curve for each specimen are basically the same.

\subsection{Influence of temperature on the bond characteristics}

\subsubsection{Hysteresis curves}

From the test results it is evident that the influence of temperature on the hysteresis curves of the specimens with different curing ages has the similar trend. Hence, in this section the typical hysteretic bond-slip curves of the specimens with 14 days curing age (see Fig. 8) are discussed in details. As can be seen from Fig. 8, under the same cooling method, the "rheostriction effect" of the hysteresis curve of the specimens increases with increasing temperature. It is clear that the area of the hysteresis loop reduces with increasing temperature. Therefore, the capacities of the restoring force and energy dissipation of the specimens decrease with increasing temperature.

Previous research indicated that the degradation of bond at high temperature is closely related to the thermal degradation of concrete [24]. This is because, when the temperature reaches $150{ }^{\circ} \mathrm{C}$, the adsorption water and free water in the concrete are evaporated and the capillary pressure of the internal pore is increased. This results some voids and cracks formed within the concrete [22]. When temperature reaches $350{ }^{\circ} \mathrm{C}$ hydrated calcium silicate, and hydrated calcium aluminate begin to dehydrate and a large amount of water vapour try to escape from the concrete. This results the sizes of cracks and pores within the concrete to be increased. Hence, the concrete strength is reduced. Another factor is due to the shrinkage of cement mortar and thermal expansion of aggregate occurs at the same time, this causes the further 
damage of concrete internal structure and concrete strength continues to fall. After the temperature of the concrete is more than $550{ }^{\circ} \mathrm{C}$, the crystallization water has completely lost. The quartz particles in the un-hydrated cement particles and aggregate are crystalized. This causes significant expansion inside the concrete. Also hydroxide is dehydrated to form free oxides and the concrete structure become considerable loose and the strength of the concrete is decreased significantly. Hence, the bonding force between concrete and reinforcing steel bars is reduced with increasing temperature. The "rheostriction effect" of the hysteresis curve of the specimens becomes more significant and the capacity of energy dissipation of the specimens is reduced considerable.

\subsubsection{Envelope curves}

As shown in Fig. 7, under the same cooling method, with the increase of heated temperature, the loading and unloading stiffness of the envelope curves of specimens are decreased. The plumpness of the envelope curves of the specimens is also decreased. It clearly shows that the capacities of the energy dissipation of the specimens are gradually reduced with increasing temperature. This is due to the strength and stiffness of concrete decreasing with creasing temperature, as discussed in Section 4.2.1.

\subsubsection{Ultimate bond stress, $\tau_{\max }$}

Fig. 9 shows the ultimate bond stresses of the specimens with different curing ages against temperature subjected to different cooling methods. It is evident that the ultimate bond stress $\tau_{\max }$ decreases with increasing temperature. As explained in Section 4.2.1, the strength of concrete degrades with increasing temperature. Previous research indicated that there is a linear relationship between the strength of concrete and the bond strength of reinforced concrete [10]. Also it is interesting to note that the degradation trends of the bond strengths for the specimens with different curing ages and cooling methods are similar.

\subsubsection{Ultimate bond slip, $S_{\max }$}

The ultimate bond slips of the specimens with different curing ages against temperature subjected different cooling methods are shown in Fig. 10. It is interesting to note that when the specimens are exposed to the temperature of $150{ }^{\circ} \mathrm{C}$, the maximum $\mathrm{S}_{\max }$ is achieved and ductility of the specimens is the best. When temperature is greater than $150{ }^{\circ} \mathrm{C}$, then the ultimate bond slips of the specimens decrease with the increasing temperature. However, for the monotonic pull out test, $S_{\max }$ is normally increased with increasing temperature [19]. 
Therefore, cyclic loading reduces the ductility of the specimens, and $\mathrm{S}_{\max }$ reduces with increasing temperature. The reasons for the maximum $S_{\max }$ achieved at $150{ }^{\circ} \mathrm{C}$ may be due to the formation of internal porosity and crack resulted by the evaporation of water in the concrete. This makes the plastic deformation of the bond is greater compared to the specimens tested at ambient temperature.

\subsection{The effect of curing age on bond characteristics}

\subsubsection{Hysteresis curves}

Fig. 11 shows the elastic-plastic hysteretic curves of the specimens exposed to $550{ }^{\circ} \mathrm{C}$ with different curing ages and subjected to air cooling. It can be seen that the area enclosed by the hysteresis curve of the specimen with 14 days curing age is the largest compared to other specimens. Hence, the capacities of the restoring force and energy dissipation of that specimen is the best among other specimens. This is because the specimen has had the most strength with 14 days curing age. Also after exposed to high temperature the heated specimen was stored under normal lab's condition for another 14 days before the test. Therefore, the strength of the specimen has got certain degree of recovery due to continue hydration within the specimen.

In contrast the specimen with 28 days curing age has the smallest area enclosed by its hysteresis curve. Therefore, its capacities of the restoring force and energy dissipation of the specimen is the worst. This is due to the specimen with 28 days curing age was tested immediately just after exposed to high temperature. There was no standing time for that specimen. Hence, the strength degraded under high temperature cannot be recovered and the loss of concrete strength was the largest.

The area enclosed by the hysteresis curve and the capacities of the restoring force and energy dissipation of the specimen with 3 days curing age are greater than that of the specimen with 7 days curing age. For the specimen with 3 days curing age has had 25 days standing time after exposed high temperature. During that period un-hydrated cement continued to hydrate and the strength of the concrete has got considerable recovery [25]. However, for the specimen with 7 days curing age, the degree of strength recovery after exposed to high temperature is considerable less than the specimen with 3 days curing age [25].

\subsubsection{Envelope curves}


Fig. 12 gives the envelope curves of the heated specimens with different curing ages subjected to air cooling. It is evident that the plumpness of the envelope curves of the specimens with 14 days curing age is the best compared to the one of the specimens with different curing ages. Hence, that specimen has got highest capacity of energy dissipation. In contrast, the specimens with 28 days curing age have had the worst plumpness of the envelope curves and the smallest capacity of energy dissipation. The plumpness of the envelope curves and the capacity of the energy dissipation of the specimens with 3 days curing age are better compared to the one of the specimens with 7 days curing age.

As discussed in Section 4.3.1, although for the specimens with 3 days curing age their strengths are lower and the material structures are loose and some voids and cracks are formed due to water evaporation at high temperature. However, after exposed to high temperature the specimens have had 25 days standing time and during this period un-hydrated cement continues to hydrate and hydrated products fill some of the voids and cracks. Hence, the strengths of the specimens have had considerable recovery. For the specimens with 7 days curing age, the concrete strength is higher compared to the specimens with 3 days curing age, but after exposed to high temperature, more voids and cracks are formed and the strength recovery during the standing time is limited. For the specimens with 14 days curing age, the specimens have had strong strength to resist high temperature and the strengths of specimens have had good recovery after high temperature. For the specimens with 28 days curing age, there is no standing time after high temperature, so the degradation of strength is worst.

\subsubsection{Ultimate bond stress, $\tau_{\max }$}

Fig. 13 shows the ultimate bond stress against curing ages for the specimens heated at different temperatures. It can be seen that at the same temperature, the changing trend of the ultimate bond stress against the curing ages for the specimens with different cooling methods are similar. The ultimate bound stress of the specimen with 14 days curing age is the largest and the ultimate bound stress of the specimen with 28 days curing age is the minimal.

For the specimen with 3 days curing age, only a proportion of cement is hydrated within the specimen. The density of the concrete is lower and internal structure of the concrete is loose. Therefore, after exposed to high temperature, due to the evaporation of a large amount of water, a lot of pore and cracks are formed within the specimen. Also the interface between cement gel and aggregate is damaged under high temperature. However, after heating the specimen was kept under normal lab's condition until 28 days, so the un-hydrated cement 
continued to hydrate during the standing time. Hence, cement hydration products filled some of the pore and cracks and the concrete strength was considerably recovered during this period.

For the specimen with 7 days curing age, the degree of hydration in concrete is relatively large compared to the specimen with 3 day curing age. However, the strength of the specimen is still not strong enough to withstand the impact of high temperature. After exposed to high temperature the degradation of concrete strength is considerable big and the recovery of the strength during the standing time is also limited. The residual strength of the specimen after high temperature is less than the one of the specimen with 3 days curing age. Hence, the ultimate bond stress of the specimen with 7 days curing age is less than the one of the specimen with 3 days curing age.

For the specimen with 14 days curing age, the degree of concrete hydration has reached $80 \%$ [26]. Therefore the specimen has got enough strength to resist high temperature. After exposed to high temperature, some un-hydrated cement particles continued to hydrate during the 14 days standing time and the certain degree of concrete strength was recovered. Hence, the ultimate bond stress of the specimen was high than the one of the specimen with 7 days curing age. For the specimen with 28 days curing age, the hydration of the concrete was almost completed. Also after high temperature, there was no standing time for the specimen. Hence, the damage of the specimen at high temperature was not able to recover. The ultimate bond stress of the specimen was the lowest.

\subsubsection{Ultimate bond slip, $S_{\max }$}

Fig. 14 shows the ultimate bond slips against curing ages for the specimens heated at high temperatures. From the figure it can be seen that the ultimate bond slip of the specimen with 14 days curing age is the largest and the one of the specimen with 28 days curing age is the lowest. This phenomenon is different with the specimens subjected to monotonic pull out test [16]. The plastic deformation of the specimen is enhanced under cyclic loading condition.

\subsection{The effect of cooling method on bond characteristics}

\subsubsection{Hysteresis curves}

Fig. 15 gives the hysteretic curves of the heated specimens with the curing age of 28 days. Form the figure it is evident that for the specimen with 28 days curing age the damage caused by water cooling is greater compared to air cooling. The surrounded area of the hysteresis 
curve of the specimen using water cooling is less than the one of the specimen by air cooling. Hence, the energy dissipation capacity of the specimen with water cooling is smaller compared to the air cooling. However, as shown in Fig. 8 for the specimen with 14 days curing age the water cooling is benefit to the strength recovery of the specimen. The surrounded area of the hysteresis curve of the specimen using water cooling is greater than the one of the specimen by air cooling. Also the energy dissipation capacity of the specimen with water cooling is greater compared to air cooling. This phenomenon was also observed for the specimens with 3 or 7 days curing ages.

\subsubsection{Envelope curves}

As shown in Fig. 7, for the specimens with the curing age less than 28 days the plumpness of the envelope curves are enhanced by using water cooling. Hence, the energy dissipation capacity of the specimen are greater compared to the specimens using air cooling. However, for the specimen with 28 days curing age water cooling has a negative impact on the envelope curve of the specimen.

\subsubsection{Ultimate bond stress, $\tau_{\max }$}

Fig. 16 presents the influences of cooling methods on the ultimate bond stresses of the heated specimens. As shown in Fig. 16, under water cooling condition the ultimate bond stresses of the specimens with the curing age less than 28 days are greater than the one of specimens using air cooling. However, for the specimen with 28 days curing age the ultimate bond stresses of the specimen using water cooling is lower than the one of the specimen by air cooling.

This is because that for the specimens with the curing age less than 28 days there are some un-hydrated cement particles within the specimens. Hence, water cooling provides extra water to enhance the continue hydration process for the un-hydrated cement particles in the specimens during the standing time which helps to recover the strength of the specimens. However, for the specimen with 28 days curing age, the hydration process was almost completed before the heating. Also the specimen was tested without any standing time. Hence water cooling cannot provide any positive impact on the strength recovery after heating. In fact, compared to air cooling water spray cooling is rapid and this results higher temperature gradient within the specimen and generates thermal stress which may cause more internal micro cracks in concrete [26]. Hence, ultimate bond stress of the specimen is less than the one of the specimens by air cooling. 


\subsubsection{Ultimate bond slip, $S_{\max }$}

Fig. 17 shows the influences of cooling methods on the ultimate bond slips of the heated specimens. It is evident that compared to air cooling for the specimens with the curing age less than 28 days the ultimate bond slips are greater under water cooling condition. However, for the specimen with 28 days curing age the ultimate bond slip using water cooling is lower compared to air cooling.

\subsection{The effect of stirrup on bond characteristics}

\subsubsection{Hysteresis curves}

Fig. 18 shows the influences of stirrup on the elastic-plastic hysteretic curves of the specimens with 14 days curing age. The same behaviour was observed in the tests for the specimens with other curing age (which are not presented here). From the figure it can be seen that the area surrounded by the hysteresis curve of the specimen with stirrup is larger than the one of the specimen without stirrup. Hence, the energy dissipation of the specimen with stirrup is bigger and the characteristics of restoring force are better than the one of specimen without stirrup. This is because the stirrup restraints concrete deformation and effectively hinder the slip between concrete and steel bar.

\subsubsection{Envelope curves}

Fig. 19 presents the influences of stirrup on the envelope curves of the specimens with 14 days curing age. The same behaviour was observed for the specimens with different curing age. As shown in the figure, the plumpness of the envelope curves for the specimen with stirrup is better compared to the one of the specimen without stirrup. Hence, the energy dissipation of the specimen with stirrup is bigger than the one of the specimen without stirrup. It is clear that under low cycle loading condition, the transverse stirrups within the specimen can effectively restraint the bond slip.

\subsubsection{Ultimate bond stress, $\tau_{\max }$}

Fig. 20 shows the influences of stirrup on the ultimate bond stresses of the specimens with 14 days curing age under air cooling and water cooling conditions. It can be seen that under low cyclic loading condition, the ultimate bond stresses of the specimens with stirrup are greater than the one of the specimens without stirrup. The influence of the stirrup on the ultimate bond stress is the same for different cooling methods. Therefore, the splitting strength or pullout strength of concrete can be improved by providing stirrup. 


\subsubsection{Ultimate bond slip, $S_{\max }$}

The influences of stirrup on the ultimate bond slips of the specimens with 14 days curing age are shown in Fig. 21. It is evident that the ultimate bond slips of the specimens with stirrup are greater than the one of the specimens without stirrup. This means that the ductility of the specimens with stirrup is better than the specimens without stirrup. Hence, stirrup enhances the bond performance under cyclic loading condition.

\section{Conclusions}

In this paper, a comprehensive experimental study has been presented to investigate the bond behaviour between early age concrete and steel bar subjected to cyclic loading after fire. Three temperatures of $150{ }^{\circ} \mathrm{C}, 350{ }^{\circ} \mathrm{C}, 550{ }^{\circ} \mathrm{C}$ and four curing ages of $3,7,14,28$ days were used. Also two cooling methods of air cooling and water cooling were adopted. The influence of transverse stirrup was investigated. Hence, a total of 32 groups of specimens were tested. In order to generate reliable test data, three identical specimens were tested for each group and average values were calculated. Based on the test results and observations the following conclusions can be drawn:

(1) Under cyclic loading condition, the residual bond strength between early age concrete and steel bar significantly reduces after exposed to high temperature. The ultimate bond stresses of the specimens with different curing age before heating decrease with increasing temperature. The ultimate bond slips of the specimens increase with temperature increasing until $150{ }^{\circ} \mathrm{C}$ then decrease with temperature further increasing. The energy dissipation capacities of the specimens decrease with increasing temperature.

(2) The curing age of specimen has considerable influence on the bond behaviour between concrete and steel bar. Compared to other three curing ages, the specimen with 14 days curing age has maximum ultimate bond stress and bond slip. The ductility and energy dissipation capacity of the specimen are greatest. In comparison, the specimen with 28 days curing age has minimum ultimate bond stress and bond slip. Also the ductility and energy dissipation capacity of the specimen are smallest.

(3) Compared to air cooling method, for the specimens with the curing ages of 3, 7, 14 days, the ultimate bond stress and bond slip are enhanced under water cooling condition. Hence, the ductility and energy dissipation capacity of the specimen are greater. However, for the specimen with the curing age of 28 days the ultimate bond stress and bond slip are 
reduced under water cooling condition. Therefore, the ductility and energy dissipation capacity of the specimen are smaller.

(4) The bond strength and ductility of the specimen with stirrup are better than the one of the specimen without stirrup. Hence, stirrup improves the bond performance of RC members under cyclic loading condition after fire.

\section{Acknowledgements}

This research was supported by the Fundamental Research Funds for the Central Universities (Grant No. 2017QNB12). The authors gratefully appreciate the support.

\section{References}

[1] L. Zhang, X. Dong and J. Xu, Reinforcing and retrofitting of an office building in Wuhan Optical Valley after fire accident, Building Structure, 37(9) (2007) 132-133. (in Chinese)

[2] C. Wu, G. Chen, J.S. Volz, R.K. Brow, M.L. Koenigstein. Local bond strength of vitreous enamel coated rebar to concrete. Construction and Building Materials, 35 (2012) 428-439.

[3] C. Wu and G. Chen. Unified model of local bond between deformed steel rebar and concrete: Indentation analogy theory and validation. Journal of Engineering Mechanics, 141(10) (2015) 04015038: 1-12.

[4] J. Xiao, Y. Hou, Z. Huang. Beam test on bond behavior between high-grade rebar and high-strength concrete after elevated temperatures. Fire Safety Journal, 69 (2014) 2335 .

[5] R. Royles, P.D. Morley. Further response of the bond in reinforced concrete to high temperatures. Magazine of Concrete Research, 35(124) (1985) 157-163.

[6] M. M. El-Hawary, S. A. Hamoush, Bond shear modulus of reinforced concrete at high temperatures, Engineering Fracture Mechanics, 55(6) (1996) 991-999.

[7] F. Bingöl and R. Gül, Residual bond strength between steel bars and concrete after elevated temperatures, Fire Safety Journal, 44(6) (2009) 854-859.

[8] H. Ş. Arel, Effect of different parameters on concrete-bar bond under high temperature, ACI Materials Journal, 111(6) (2014).

[9] Ergün, G. Kürklü, M. S. Başpınar, The effects of material properties on bond strength 
between reinforcing bar and concrete exposed to high temperature, Construction \& Building Materials, 112 (2016) 691-698.

[10] R. H. Haddad, L. G. Shannis, Post-fire behavior of bond between high strength pozzolanic concrete and reinforcing steel, Construction \& Building Materials, 18(6) (2004) 425-435.

[11] H. Yang, W. Lan, Y. Qin, J. Wang, Evaluation of bond performance between deformed bars and recycled aggregate concrete after high temperatures exposure, Construction \& Building Materials, 112 (2016) 885-891.

[12] Z. Huang, Modelling the bond between concrete and reinforcing steel in a fire, Engineering Structures, 32(11) (2010) 3660-3669.

[13] J. Khalaf, Z. Huang, M. Fan, Analysis of bond-slip between concrete and steel bar in fire, Computers \& Structures, 162 (2016) 1-15.

[14] T. Pothisiri and P. Panedpojaman, Modeling of bonding between steel rebar and concrete at elevated temperatures, Construction \& Building Materials, 27(1) (2012) 130-140.

[15] V. K. R. Kodur and A. Agrawal, Effect of temperature induced bond degradation on fire response of reinforced concrete beams, Engineering Structures, 142 (2017) 98-109.

[16] Q. Li, X. Huang, Z. Huang, G. Yuan, Bond characteristics between early aged fly ash concrete and reinforcing steel bar after fire, Construction \& Building Materials, 147 (2017) 701-712.

[17] GB 50152-92 Standard for Test Method of Concrete Structures, Ministry of Housing and Urban-rural Development of China, Sun Yat-Sen University Press, Guangzhou, 1992.

[18] X. Li, Y. Bao, N. Xue, G. Chen, Bond strength of steel bars embedded in highperformance fiber-reinforced cementitious composite before and after exposure to elevated temperatures, Fire Safety Journal, 92 (2017) 98-106.

[19] X. Fu and D. D. L. Chung, Decrease of the bond strength between steel rebar and concrete with increasing curing age, Cement \& Concrete Research, 28(2) (1998) 167-169. 
[20] X. Tang, Y. Qin, W. Qu, Experimental study on time-varying regularity of compressive and bond strength of concrete at early-age, Journal of Building Structures, 4, (2009) 145-150. (in Chinese)

[21] K. Hertz, The anchorage capacity of reinforcing bars at normal and high temperatures, Magazine of Concrete Research, 34(121) (1982) 213-220.

[22] B. Chen, C. Li, L. Chen, Experimental study of mechanical properties of normal-strength concrete exposed to high temperatures at an early age. Fire Safety Journal, 44(7) (2009) 997-1002.

[23] V. Ciampi, R. Eligehausen, V.V. Bertero, E. P. Popov. Analytical model for concrete anchorages of reinforcing bars under generalized excitations. Report No. UCB/EERC-82/23, College of Engineering, University of California, Berkeley, California (1982).

[24] X. Li, Y. Bao, L. Wu, Q. Yan, H. Ma, G. Chen, H. Zhang. Thermal and mechanical properties of high-performance fiber-reinforced cementitious composites after exposure to high temperatures. Construction and Building Materials, 157 (2017) $829-838$.

[25] Q. Li, L. Liu, Z. Huang, G. Yuan. Residual compressive strength of cementbased grouting material with early ages after fire. Construction \& Building Materials, 138 (2017) 316-325.

[26] W. Jiang, G. D. Schutter, Y. Yuan, Degree of hydration based prediction of early age basic creep and creep recovery of blended concrete, Cement \& Concrete Composites, 48(2) (2014) 83-90.

T. Gupta, S. Siddique, R. K. Sharma, S. Chaudhary, Effect of elevated temperature and cooling regimes on mechanical and durability properties of concrete containing waste rubber fiber, Construction \& Building Materials, 137 (2017) 35-45. 


\section{Figure and table captions}

Table 1 Mix design of concrete.

Table 2 Chemical composition of cement.

Table 3 Particle size distribution of coarse aggregate and fine aggregate.

Table 4 Detailed characteristics and mechanical properties of steel bar and stirrup.

Table 5 List of specimens' groups.

Table 6 Heating procedure.

Table 7 Compressive strength of concrete immediately after cooling.

Table 8 Compressive strength of concrete heated at different early age

Table 9 Ultimate bond stresses and slips of the specimens.

Fig. 1 Details of the specimens.

Fig. 2 Test rig.

Fig. 3 Cyclic loading set-up.

Fig. 4 Cyclic loading procedure.

Fig. 5 The hysteretic bond-slip curve of F28d350S-H.

Fig. 6 Hysteretic curves at different stages.

Fig. 7 Envelope curves of the specimens.

Fig. 8 Elastic-plastic hysteretic curves of the heated specimens with 14 days curing age.

Fig. 9 The ultimate bond stresses of the specimens with different curing ages against temperature.

Fig. 10 The ultimate bond slips of the specimens with different curing ages against temperature.

Fig. 11 Elastic-plastic hysteretic curves of the heated specimens with different curing ages.

Fig. 12 Envelope curves of the heated specimens with different curing ages.

Fig. 13 The ultimate bond stresses against curing ages for the specimens heated at high temperatures. 
Fig. 14 The ultimate bond slips against curing ages for the specimens heated at high temperatures.

Fig. 15 Elastic-plastic hysteretic curves of the heated specimens with the curing age of 28 days.

Fig. 16 Influences of cooling methods on the ultimate bond stresses of the heated specimens.

Fig. 17 Influences of cooling methods on the ultimate bond slips of the heated specimens.

Fig. 18 Influences of stirrup on the elastic-plastic hysteretic curves of the specimens.

Fig. 19 Influences of stirrup on the envelope curves of the specimens with 14 days curing age.

Fig. 20 Influences of stirrup on the ultimate bond stresses of the heated specimens with 14 days curing age.

Fig. 21 Influences of stirrup on the ultimate bond slips of the heated specimens with 14 days curing age. 


\section{Tables}

Table 1 Mix design of concrete.

\begin{tabular}{ccccccc}
\hline \multicolumn{4}{c}{ Constituent $\left(\mathrm{kg} / \mathrm{m}^{3}\right)$} & $\begin{array}{c}\text { Water to } \\
\text { cement ratio }\end{array}$ & Sand ratio (\%) & $\begin{array}{c}\text { Compressive strength } \\
\text { at 28 }\end{array}$ \\
\cline { 1 - 5 } Cement & Water & Sand & Coarse aggregate & \\
\hline 305 & 183 & 740 & 1056 & 0.60 & 41.2 & 33.2 \\
\hline
\end{tabular}

Table 2 Chemical composition of cement (\%).

\begin{tabular}{cccccccc}
\hline $\mathrm{SiO}_{2}$ & $\mathrm{Al}_{2} \mathrm{O}_{3}$ & $\mathrm{Fe}_{2} \mathrm{O}_{3}$ & $\mathrm{CaO}$ & $\mathrm{MgO}$ & $\mathrm{SO}_{3}$ & Free $\mathrm{CaO}$ & Loss on ignitiong \\
\hline 22.36 & 5.68 & 4.13 & 60.12 & 1.49 & 2.47 & 0.12 & 1.98 \\
\hline
\end{tabular}

Table 3 Particle size distribution of coarse aggregate and fine aggregate.

\begin{tabular}{l|c|c|c|c|c|c|c}
\hline \multirow{2}{*}{ Coarse aggregate } & Sieve diameter (mm) & 25.0 & 20.0 & 16.0 & 10.0 & 5.00 & 2.50 \\
\cline { 2 - 8 } & Accumulated sieve residue (\%) & $/$ & 0 & 3 & 38 & 94 & 99 \\
\hline \multirow{2}{*}{ Fine aggregate } & Sieve diameter (mm) & 5.00 & 2.50 & 1.25 & 0.63 & 0.32 & 0.16 \\
\cline { 2 - 8 } & Accumulated sieve residue (\%) & 1 & 19 & 41 & 52 & 72 & 89 \\
\hline
\end{tabular}

Table 4 Detailed characteristics and mechanical properties of steel bar and stirrup.

\begin{tabular}{lll}
\hline Type of steel bar & Reinforcement & Stirrup \\
\hline Strength grade & HRB400 & HPB300 \\
Nominal diameter (mm) & 16 & 6 \\
Core diameter $(\mathrm{mm})$ & 15.4 & - \\
Average rib depth (mm) & 1.4 & - \\
Base rib width (mm) & 3.6 & - \\
Top rib width $(\mathrm{mm})$ & 0.9 & - \\
Rib spacing $(\mathrm{mm})$ & 11.0 & - \\
Rib face angle $\left({ }^{\circ}\right)$ & 49 & - \\
Relative rib area & 0.08 & - \\
Cross-sectional area $\left(\mathrm{mm}^{2}\right)$ & 201.1 & 28.3 \\
Nominal Young modulus $(\mathrm{GPa})$ & 200.5 & 200.5 \\
Measured yield strength $(\mathrm{MPa})$ & 407 & 312 \\
Measured ultimate strength $(\mathrm{MPa})$ & 512 & 382 \\
Elongation percentage $(\%)$ & 15.9 & 17.1 \\
\hline
\end{tabular}


Table 5 List of specimens' groups.

\begin{tabular}{|c|c|c|c|c|}
\hline Group number & Curing age (day) & $\begin{array}{c}\text { Temperature } \\
\left({ }^{\circ} \mathrm{C}\right)\end{array}$ & Cooling method & Stirrup \\
\hline F0-H & 28 & 20 & - & Yes \\
\hline F0 & 28 & 20 & - & No \\
\hline F3d150Z-H & \multirow{6}{*}{3} & 150 & Air cooling & Yes \\
\hline F3d350Z-H & & 350 & Air cooling & Yes \\
\hline F3d550Z-H & & 550 & Air cooling & Yes \\
\hline F3d150S-H & & 150 & Water cooling & Yes \\
\hline F3d350S-H & & 350 & Water cooling & Yes \\
\hline F3d550S-H & & 550 & Water cooling & Yes \\
\hline F7d150Z-H & \multirow{6}{*}{7} & 150 & Air cooling & Yes \\
\hline F7d350Z-H & & 350 & Air cooling & Yes \\
\hline F7d550Z-H & & 550 & Air cooling & Yes \\
\hline F7d150S-H & & 150 & Water cooling & Yes \\
\hline F7d350S-H & & 350 & Water cooling & Yes \\
\hline F7d550S-H & & 550 & Water cooling & Yes \\
\hline F14d150Z & \multirow{12}{*}{14} & 150 & Air cooling & No \\
\hline F14d350Z & & 350 & Air cooling & No \\
\hline F14d550Z & & 550 & Air cooling & No \\
\hline F14d150S & & 150 & Water cooling & No \\
\hline F14d350S & & 350 & Water cooling & No \\
\hline F14d550S & & 550 & Water cooling & No \\
\hline F14d150Z-H & & 150 & Air cooling & Yes \\
\hline F14d350Z-H & & 350 & Air cooling & Yes \\
\hline F14d550Z-H & & 550 & Air cooling & Yes \\
\hline F14d150S-H & & 150 & Water cooling & Yes \\
\hline F14d350S-H & & 350 & Water cooling & Yes \\
\hline F14d550S-H & & 550 & Water cooling & Yes \\
\hline F28d150Z-H & \multirow{6}{*}{28} & 150 & Air cooling & Yes \\
\hline F28d350Z-H & & 350 & Air cooling & Yes \\
\hline F28d550Z-H & & 550 & Air cooling & Yes \\
\hline F28d150S-H & & 150 & Water cooling & Yes \\
\hline F28d350S-H & & 350 & Water cooling & Yes \\
\hline F28d550S-H & & 550 & Water cooling & Yes \\
\hline
\end{tabular}

Table 6 Heating procedure.

\begin{tabular}{ccc}
\hline $\begin{array}{c}\text { Temperature } \\
\left({ }^{\circ} \mathrm{C}\right)\end{array}$ & Heating time $(\min )$ & Maintaining time (min) \\
\hline 150 & 15 & 90 \\
350 & 35 & 90 \\
550 & 55 & 90 \\
\hline
\end{tabular}


Table 7 Compressive Strength of Concrete immediately after Cooling.

\begin{tabular}{|c|c|c|c|c|}
\hline \multirow{2}{*}{$\begin{array}{c}\text { Initial curing } \\
\text { (days) }\end{array}$} & \multirow{2}{*}{$\begin{array}{c}f_{\text {cu }} \\
(\mathrm{MPa})\end{array}$} & \multirow{2}{*}{$\begin{array}{c}\text { Temperature } \\
\left({ }^{\circ} \mathrm{C}\right)\end{array}$} & \multicolumn{2}{|c|}{$f_{\text {cut0 }}(\mathrm{MPa})$} \\
\hline & & & Air cooling & Water cooling \\
\hline \multirow{3}{*}{3} & \multirow{3}{*}{$f_{\mathrm{cu} 3}=11.9$} & 150 & 14.8 & 16.1 \\
\hline & & 350 & 13.4 & 14.2 \\
\hline & & 550 & 7.4 & 8.4 \\
\hline \multirow{3}{*}{7} & \multirow{3}{*}{$f_{\mathrm{cu} 7}=22.2$} & 150 & 24.4 & 25.1 \\
\hline & & 350 & 22.4 & 23.1 \\
\hline & & 550 & 18.9 & 19.7 \\
\hline \multirow{3}{*}{14} & \multirow{3}{*}{$f_{\text {cu14 }}=27.6$} & 150 & 29.3 & 29.5 \\
\hline & & 350 & 27.0 & 28.4 \\
\hline & & 550 & 21.4 & 22.1 \\
\hline \multirow{3}{*}{28} & \multirow{3}{*}{$f_{\text {cu28 }}=33.2$} & 150 & 28.9 & 27.2 \\
\hline & & 350 & 23.6 & 22.6 \\
\hline & & 550 & 19.9 & 19.3 \\
\hline
\end{tabular}

Here, $f_{\text {cuT0 }}$ is the compressive strength of early-age specimens immediately after cooling, $f_{\text {cu }}$ (Including $f_{\text {cu } 3}, f_{\text {cu } 7}$, $f_{\text {cu14 }}, f_{\text {cu28, }}$ ) is the compressive strength of un-heated specimens which are respectively tested at $3^{\text {rd }}, 7^{\text {th }}, 14^{\text {th }}$ and $28^{\text {th }}$ day after casting.

Table 8 Compressive Strength of Concrete Heated at Different Early Age (Age of 28 days since casting, $f_{\mathrm{cu} 28}=33.2 \mathrm{MPa}, f_{\mathrm{t} 28}=3.27 \mathrm{MPa}$ )

\begin{tabular}{|c|c|c|c|c|c|c|}
\hline \multirow{2}{*}{$\begin{array}{l}\text { Initial curing } \\
\text { (days) }\end{array}$} & \multirow{2}{*}{$\begin{array}{l}\text { Rest period } \\
\text { (days) }\end{array}$} & \multirow{2}{*}{$\begin{array}{c}\text { Temperature } \\
\left({ }^{\circ} \mathrm{C}\right)\end{array}$} & \multicolumn{2}{|c|}{$f_{\text {cuT28 }}(\mathrm{MPa})$} & \multicolumn{2}{|c|}{$f_{\mathrm{tT} 28}(\mathrm{MPa})$} \\
\hline & & & Air cooling & Water cooling & Air cooling & Water cooling \\
\hline \multirow{3}{*}{3} & \multirow{3}{*}{25} & 150 & 30.1 & 31.3 & 2.72 & 3.01 \\
\hline & & 350 & 27.9 & 28.5 & 2.39 & 2.63 \\
\hline & & 550 & 22.0 & 24.2 & 1.98 & 2.16 \\
\hline \multirow{3}{*}{7} & \multirow{3}{*}{21} & 150 & 28.6 & 30.3 & 2.67 & 2.95 \\
\hline & & 350 & 25.3 & 27.2 & 2.14 & 2.27 \\
\hline & & 550 & 20.5 & 21.0 & 1.73 & 2.02 \\
\hline \multirow{3}{*}{14} & \multirow{3}{*}{14} & 150 & 30.0 & 31.7 & 2.88 & 3.05 \\
\hline & & 350 & 27.9 & 29.2 & 2.54 & 2.72 \\
\hline & & 550 & 22.9 & 24.2 & 2.06 & 2.21 \\
\hline \multirow{3}{*}{28} & \multirow{3}{*}{0} & 150 & 28.9 & 27.2 & 2.55 & 2.65 \\
\hline & & 350 & 23.6 & 22.6 & 2.09 & 2.17 \\
\hline & & 550 & 20.1 & 19.1 & 1.67 & 1.54 \\
\hline
\end{tabular}

Here, $f_{\text {cuT28 }}$ is the compressive strength of early-age specimens cured for less than 28 days before heating, $f_{\mathrm{t} 228}$ is the tensile strength of early-age specimens on the 28th day after being heated at its early age. 
Table 9 Ultimate bond stresses and slips of the specimens.

\begin{tabular}{cccccccc}
\hline $\begin{array}{c}\text { Group } \\
\text { number }\end{array}$ & $\begin{array}{c}\tau_{\max } \\
(\mathrm{MPa})\end{array}$ & $\begin{array}{c}\tau_{\max /} \\
f_{\text {cuT28 }}\end{array}$ & $\begin{array}{c}\mathrm{S}_{\max } \\
(\mathrm{mm})\end{array}$ & $\begin{array}{c}\text { Group } \\
\text { number }\end{array}$ & $\begin{array}{c}\tau_{\max } \\
(\mathrm{MPa})\end{array}$ & $\begin{array}{c}\tau_{\max /} \\
f_{\text {cuT28 }}\end{array}$ & $\begin{array}{c}\mathrm{S}_{\max } \\
(\mathrm{mm})\end{array}$ \\
\hline F0-H & 7.80 & 0.23 & 0.88 & F0 & 7.53 & 0.24 & 0.81 \\
F3d150Z-H & 7.15 & 0.24 & 0.97 & F3d150S-H & 7.40 & 0.24 & 0.99 \\
F3d350Z-H & 5.54 & 0.20 & 0.85 & F3d350S-H & 6.11 & 0.21 & 0.89 \\
F3d550Z-H & 3.69 & 0.17 & 0.69 & F3d550S-H & 4.00 & 0.17 & 0.76 \\
F7d150Z-H & 6.73 & 0.24 & 0.92 & F7d150S-H & 7.00 & 0.23 & 0.95 \\
F7d350Z-H & 5.12 & 0.20 & 0.72 & F7d350S-H & 5.49 & 0.20 & 0.77 \\
F7d550Z-H & 3.08 & 0.15 & 0.56 & F7d550S-H & 3.56 & 0.17 & 0.64 \\
F14d150Z & 6.84 & 0.23 & 0.93 & F14d150S & 7.01 & 0.22 & 0.97 \\
F14d350Z & 5.52 & 0.20 & 0.79 & F14d350S & 6.34 & 0.22 & 0.85 \\
F14d550Z & 3.47 & 0.15 & 0.61 & F14d550S & 3.75 & 0.15 & 0.68 \\
F14d150Z-H & 7.27 & 0.24 & 1.01 & F14d150S-H & 7.80 & 0.25 & 1.06 \\
F14d350Z-H & 6.00 & 0.22 & 0.85 & F14d350S-H & 6.55 & 0.22 & 0.90 \\
F14d550Z-H & 3.60 & 0.16 & 0.66 & F14d550S-H & 4.46 & 0.18 & 0.70 \\
F28d150Z-H & 6.30 & 0.22 & 0.93 & F28d150S-H & 6.07 & 0.22 & 0.91 \\
F28d350Z-H & 4.71 & 0.20 & 0.77 & F28d350S-H & 4.20 & 0.19 & 0.68 \\
F28d550Z-H & 2.80 & 0.14 & 0.54 & F28d550S-H & 2.04 & 0.11 & 0.51 \\
\hline
\end{tabular}




\section{Figures}

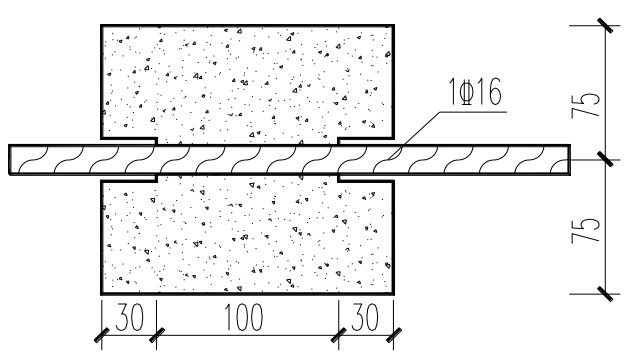

(a) Dimensions of the specimen

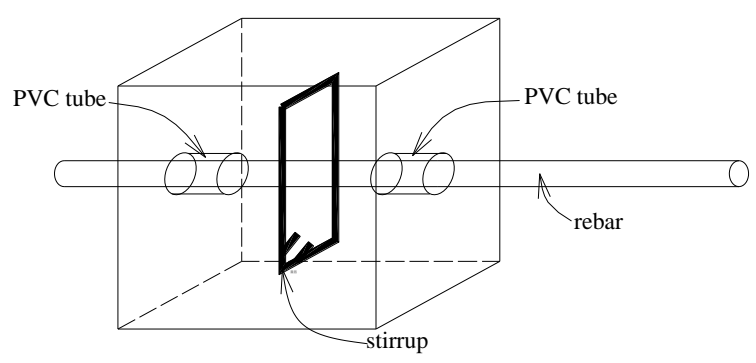

(b) Position of the stirrup

Fig. 1 Details of the specimens (all dimensions in $\mathrm{mm}$ ).

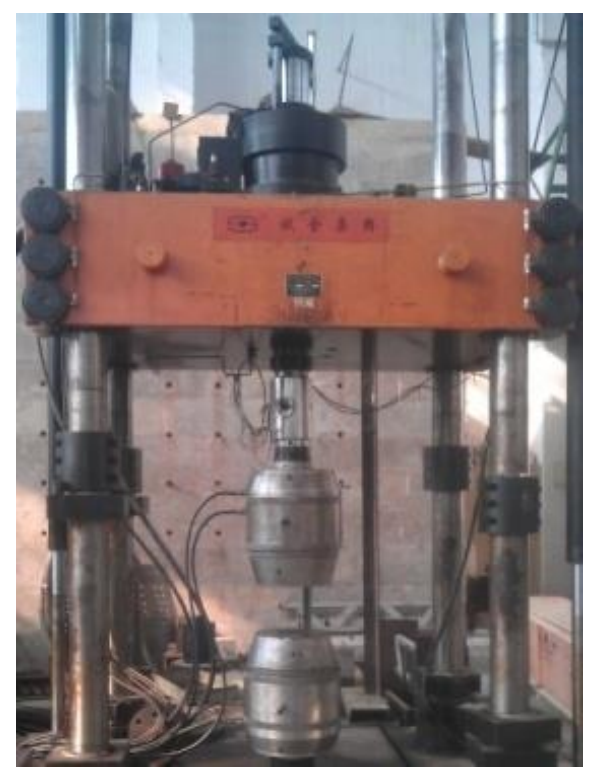

Fig. 2 Test rig. 


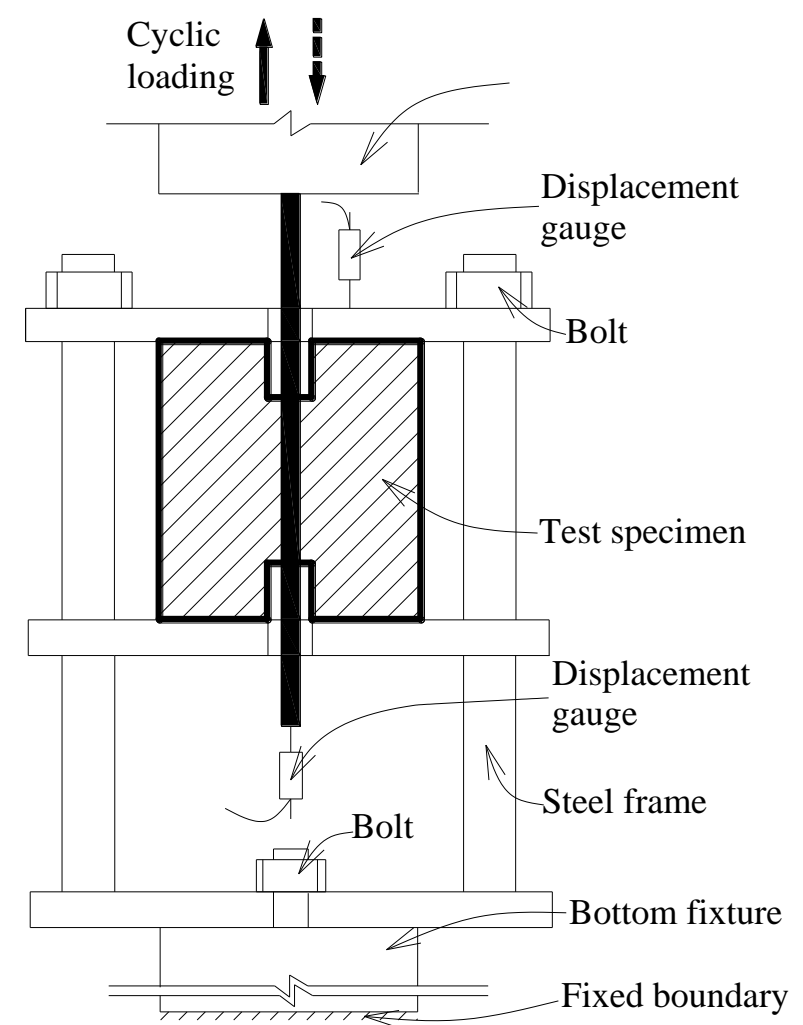

Fig. 3 Cyclic loading set-up.

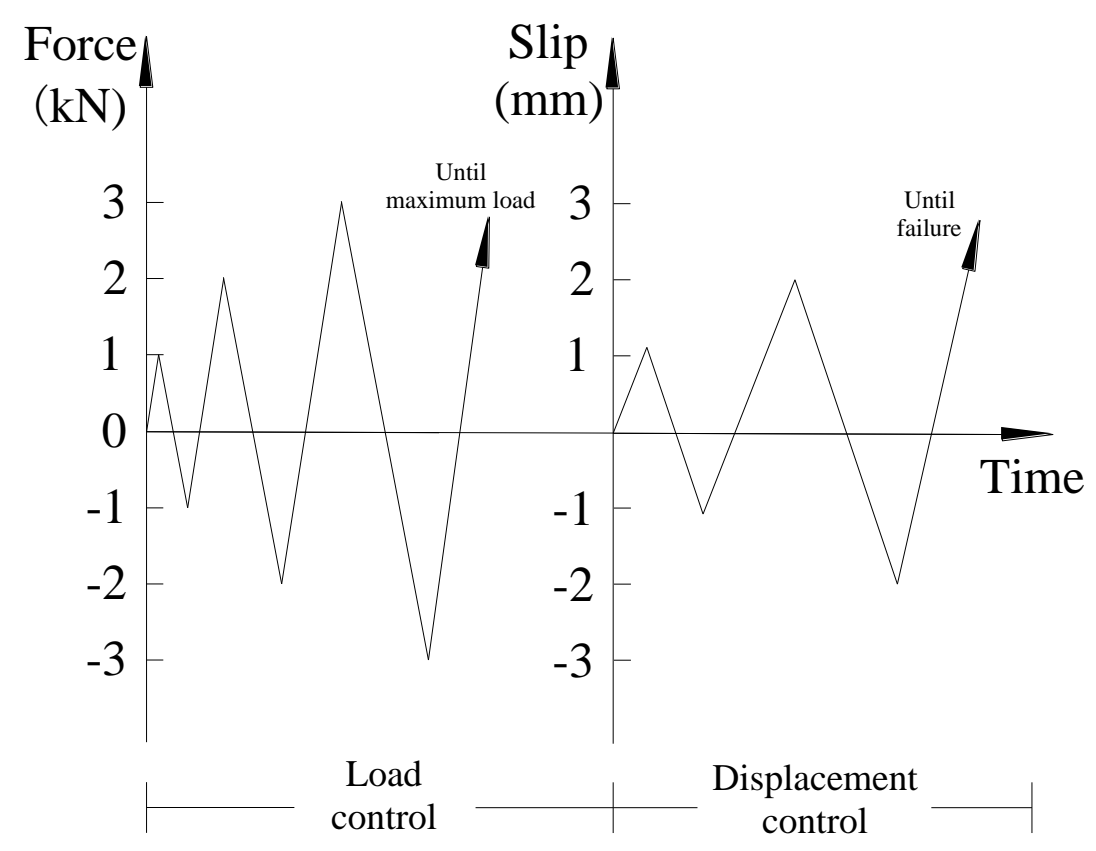

Fig. 4 Cyclic loading procedure. 


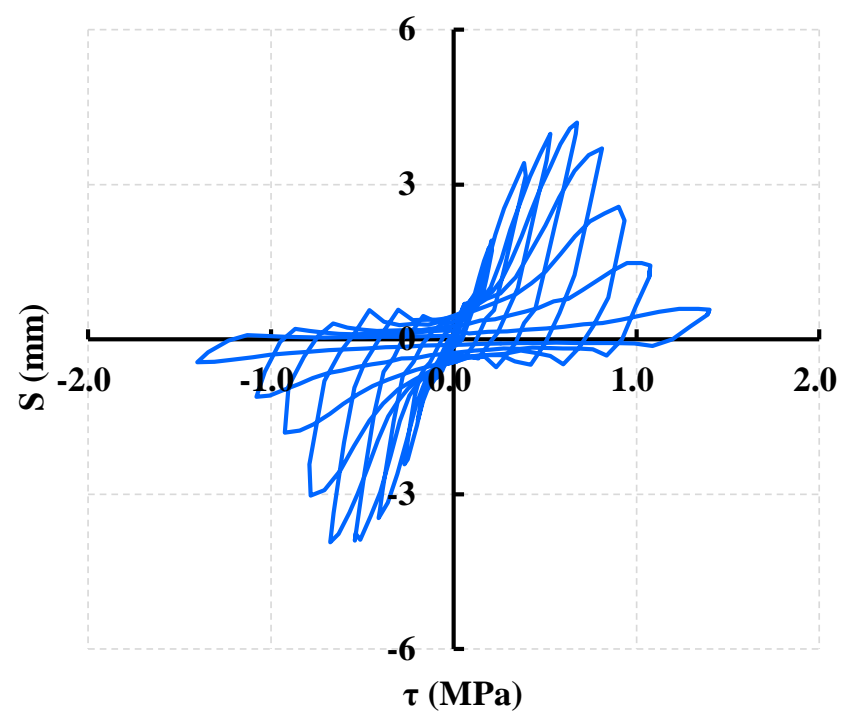

Fig. 5 The hysteretic bond-slip curve of F28d350S-H.

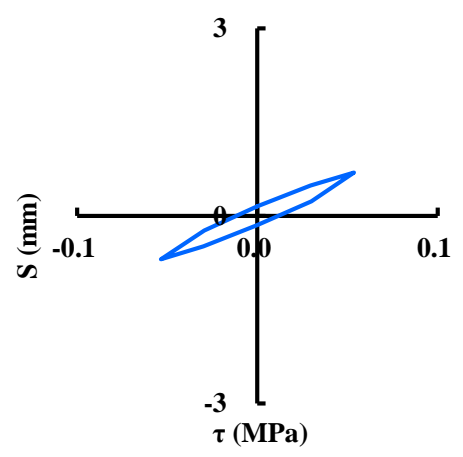

(a) Elastic stage

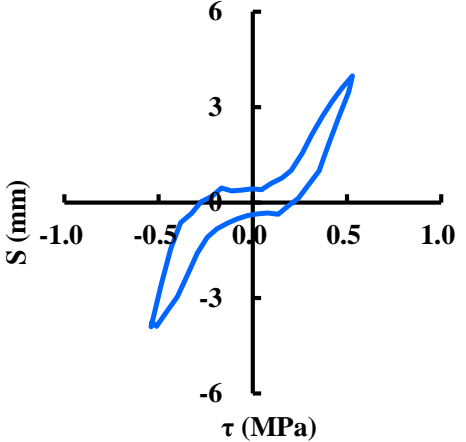

(b) Elastic-plastic stage

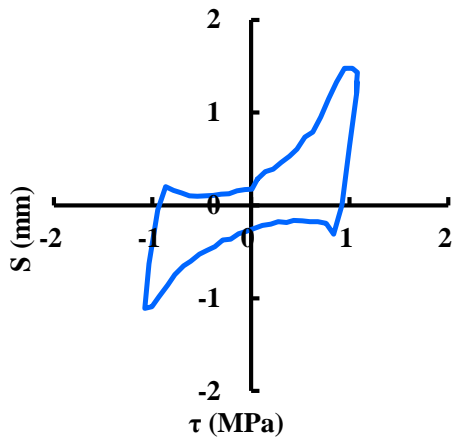

(c) Failure stage

Fig. 6 Hysteretic curves at different stages. 


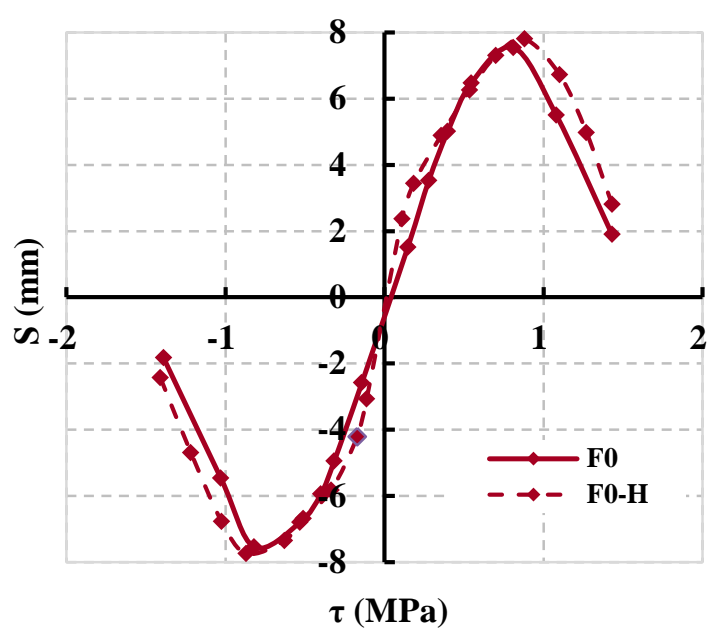

(a) Control specimens at $20{ }^{\circ} \mathrm{C}$

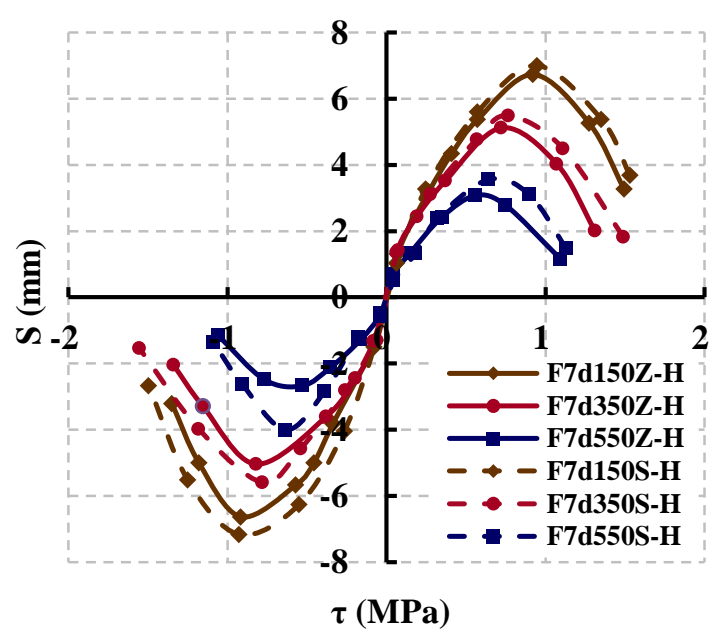

(c) 7 days of curing age with stirrup and heated

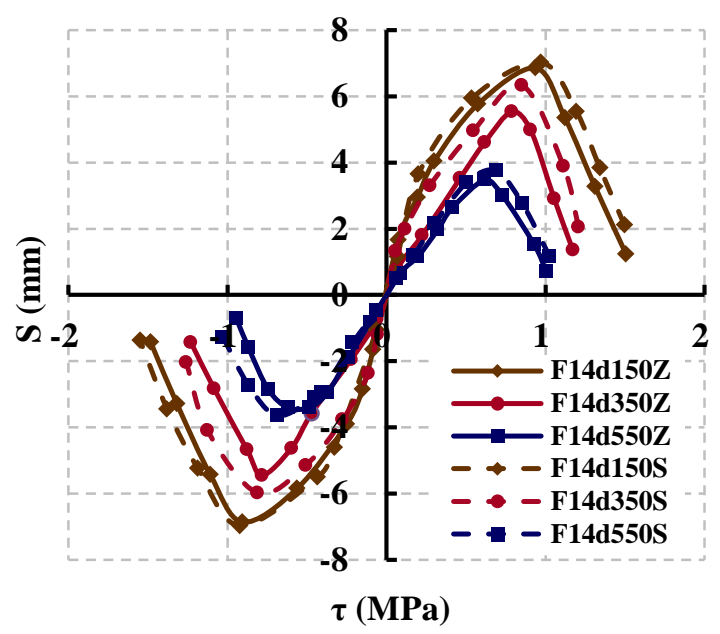

(e) 14 days of curing age without stirrup and heated

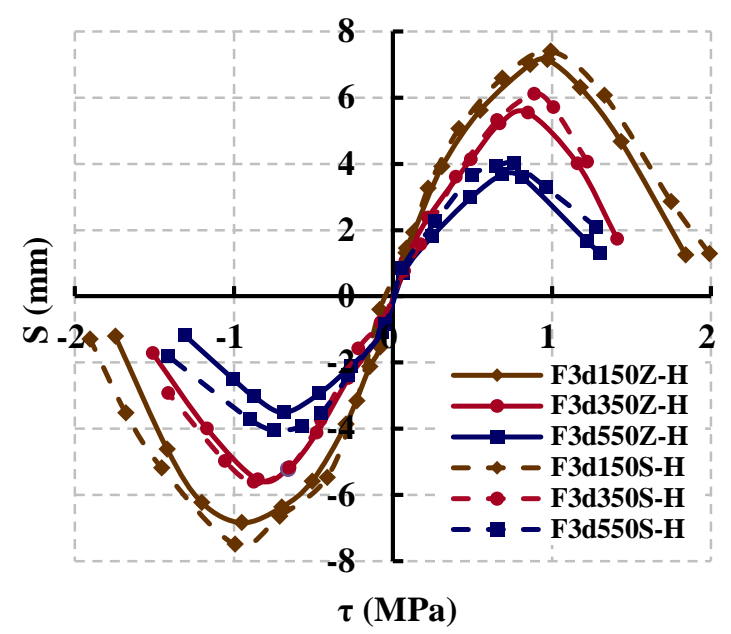

(b) 3 days of curing age with stirrup and heated

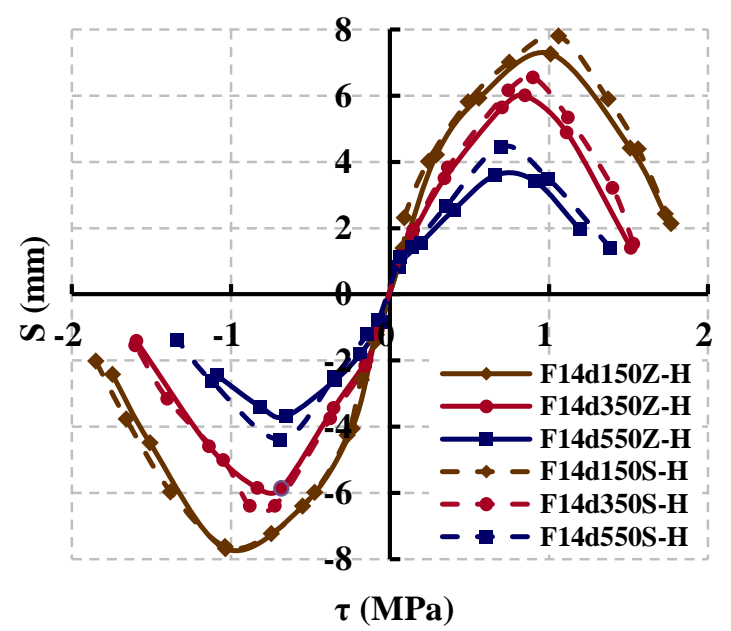

(d) 14 days of curing age with stirrup and heated

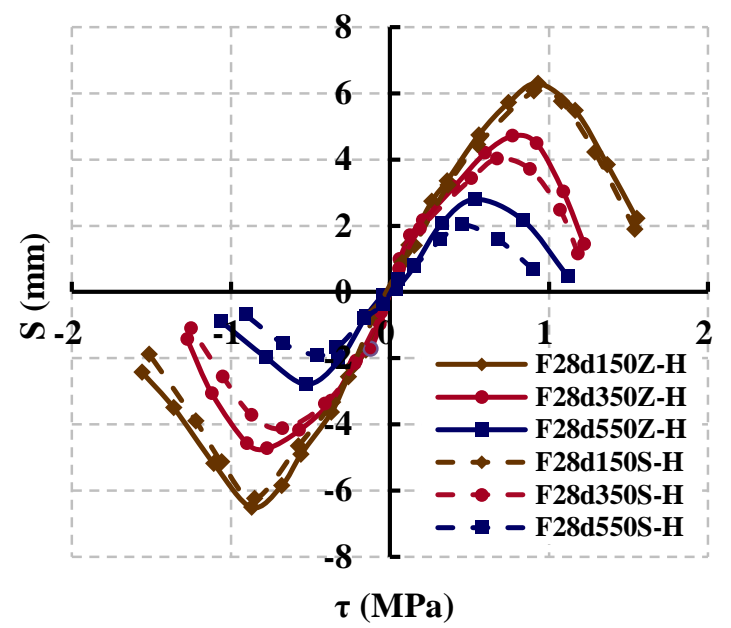

(f) 28 days of curing age with stirrup and heated

Fig. 7 Envelope curves of the specimens. 


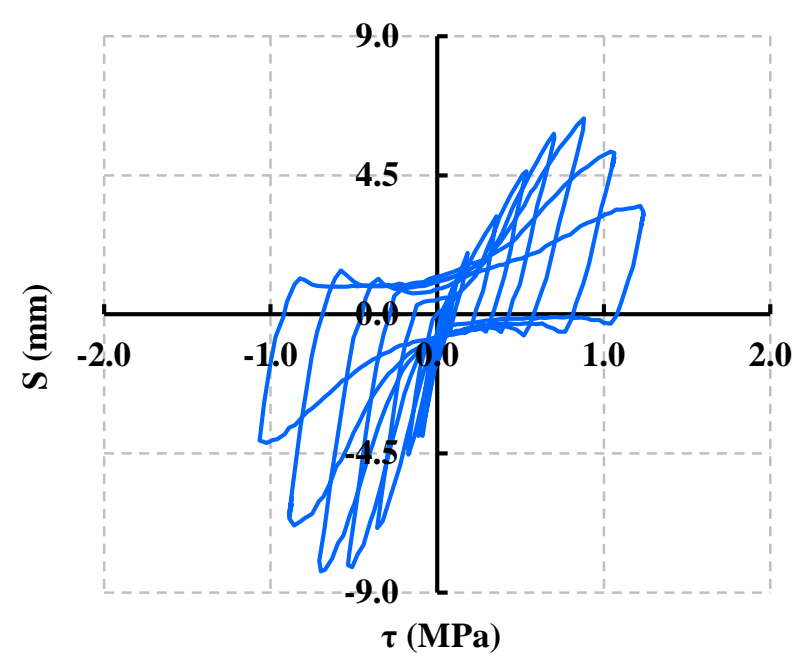

(a) $\mathrm{F} 0-\mathrm{H}$

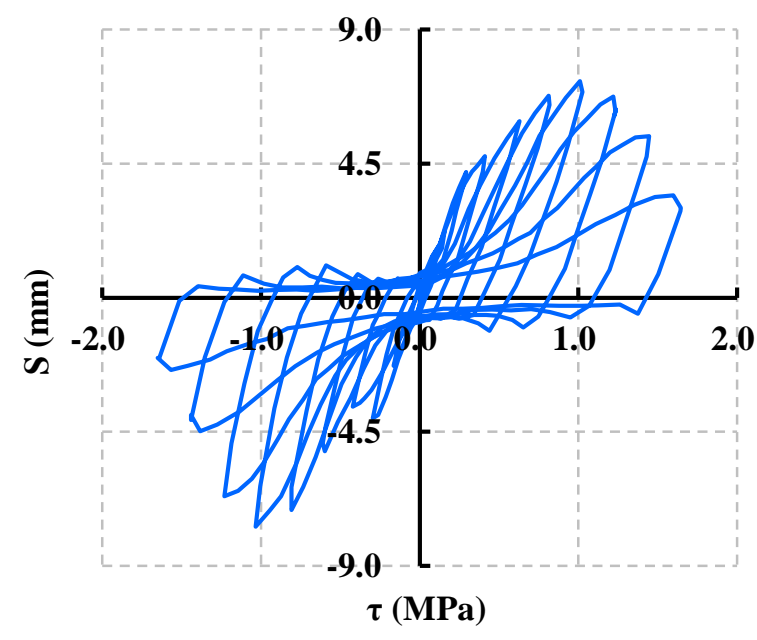

(b) F14d150Z-H

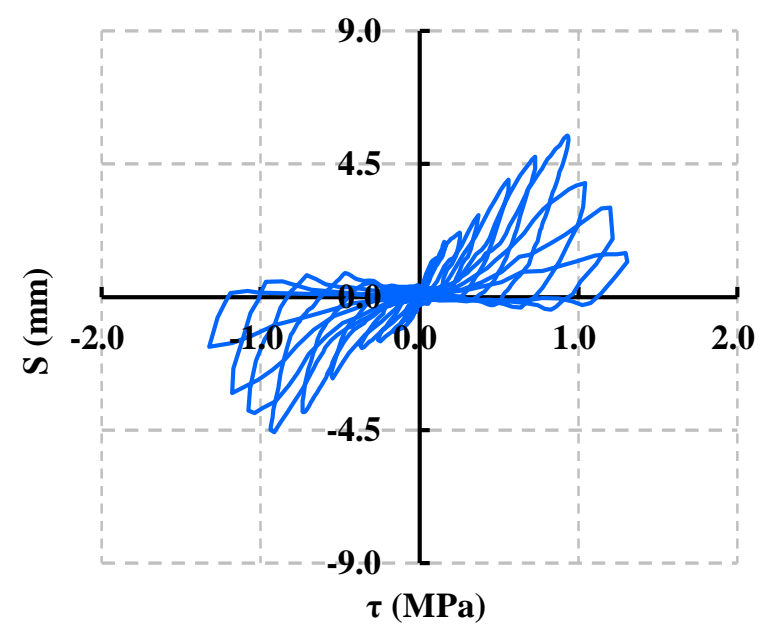

(d) F14d350Z-H

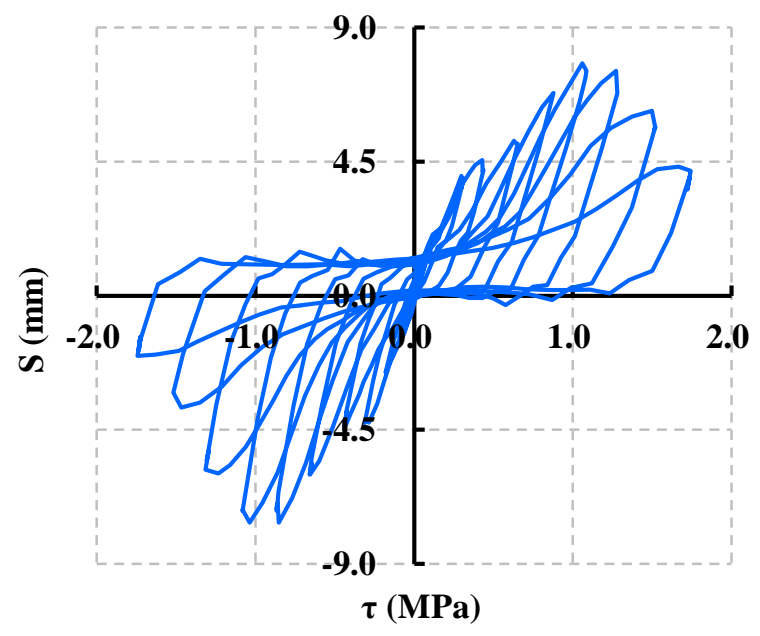

(c) F14d150S-H

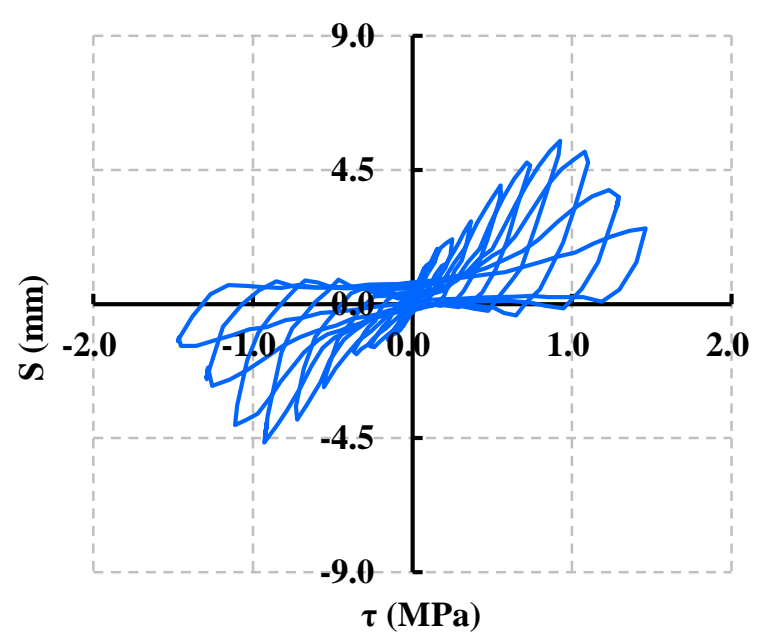

(e) F14d350S-H 


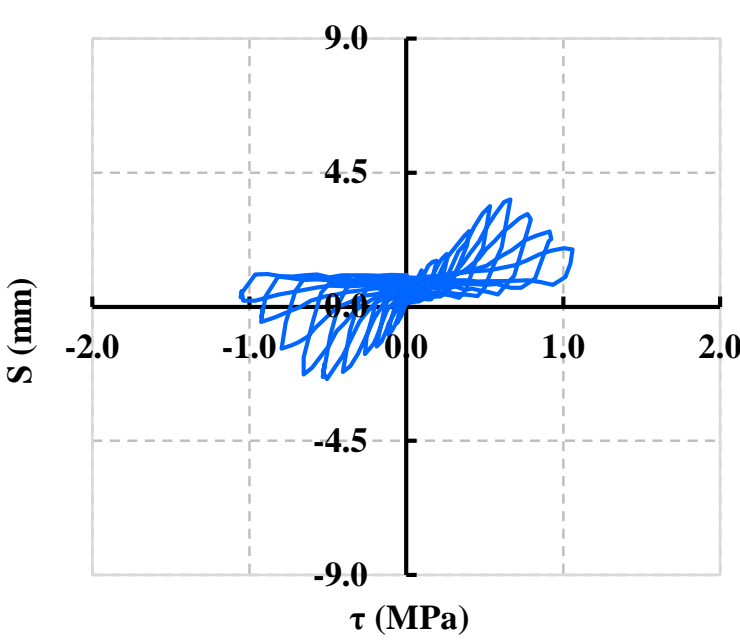

(f) F14d550Z-H

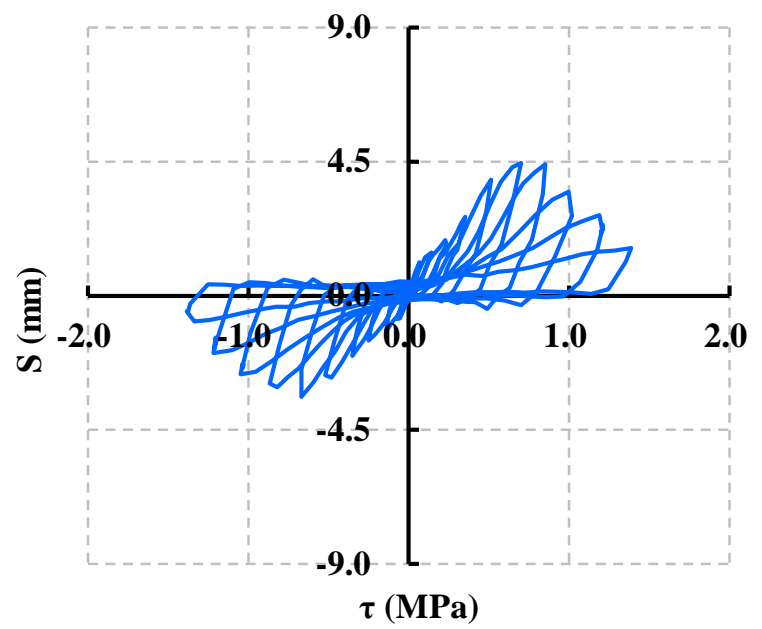

(g) F14d550S-H

Fig. 8 Elastic-plastic hysteretic curves of the heated specimens with 14 days curing age.

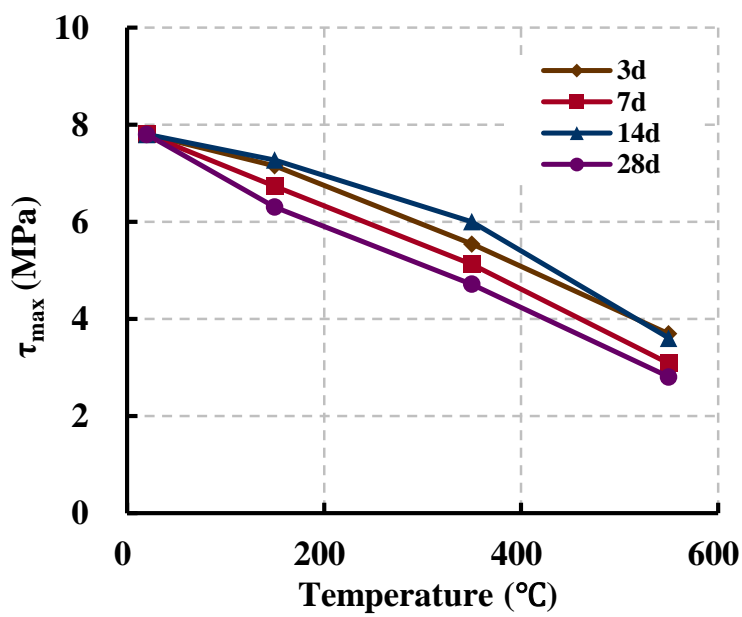

(a) Air cooling

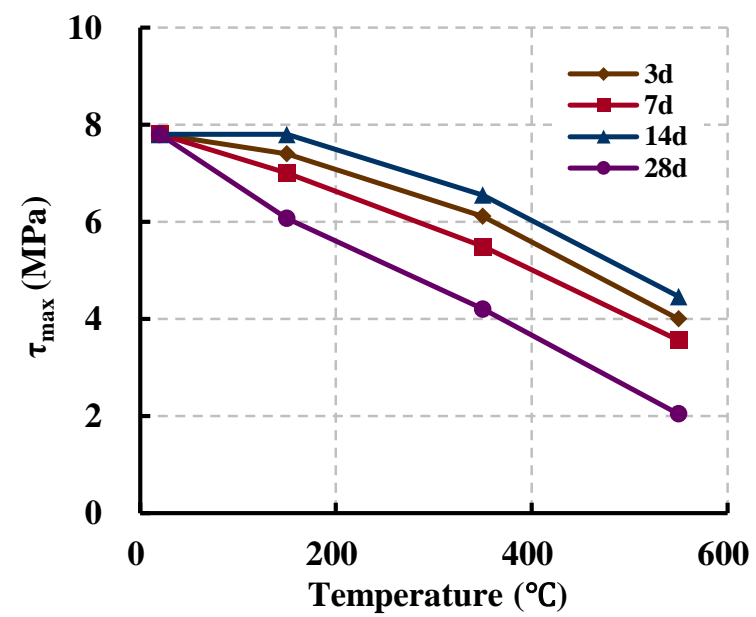

(b) Water cooling

Fig. 9 The ultimate bond stresses of the specimens with different curing ages $(\mathrm{d}=$ days) against temperature. 


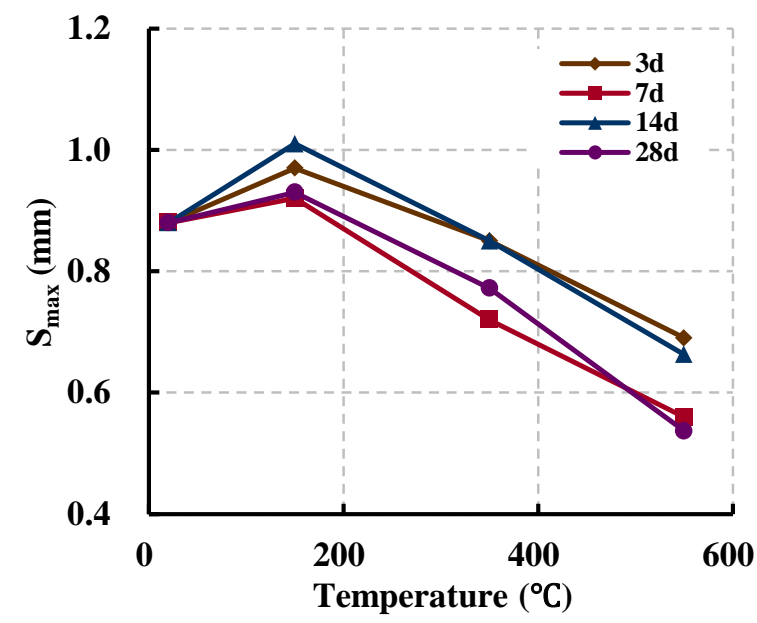

(a) Air cooling

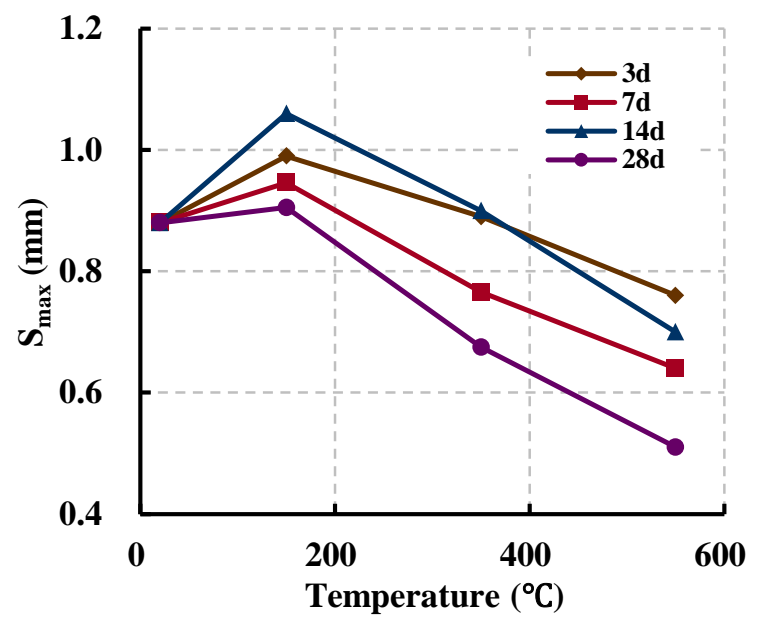

(b) Water cooling

Fig. 10 The ultimate bond slips of the specimens with different curing ages $(d=$ days $)$ against temperature.

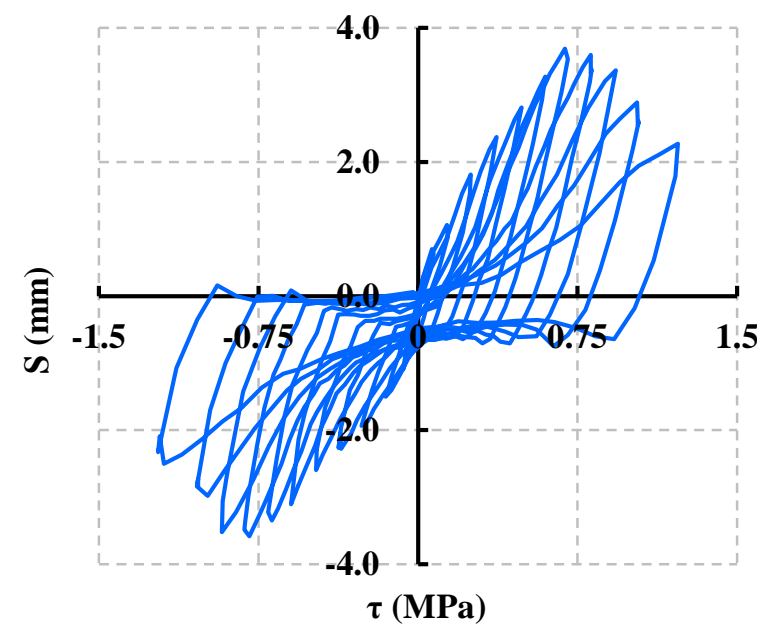

(a) F3d550Z-H

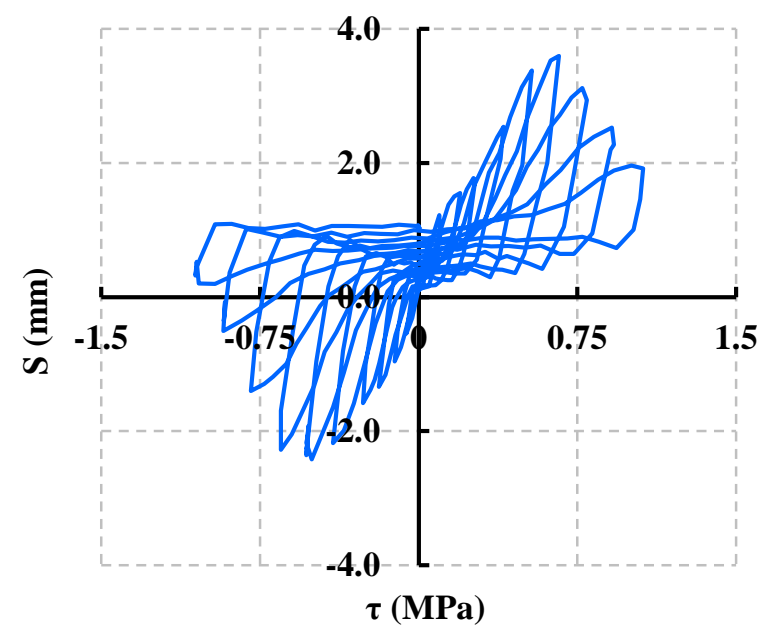

(c) F14d550Z-H

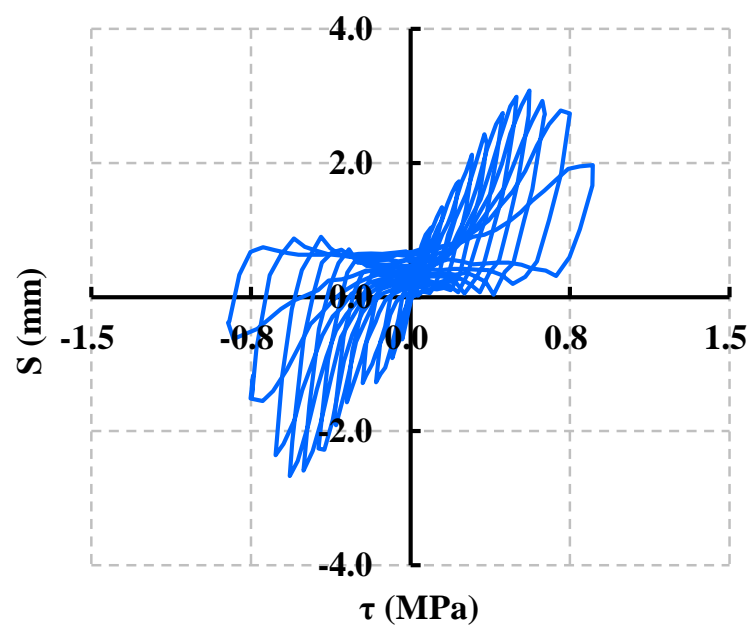

(b) F7d550Z-H

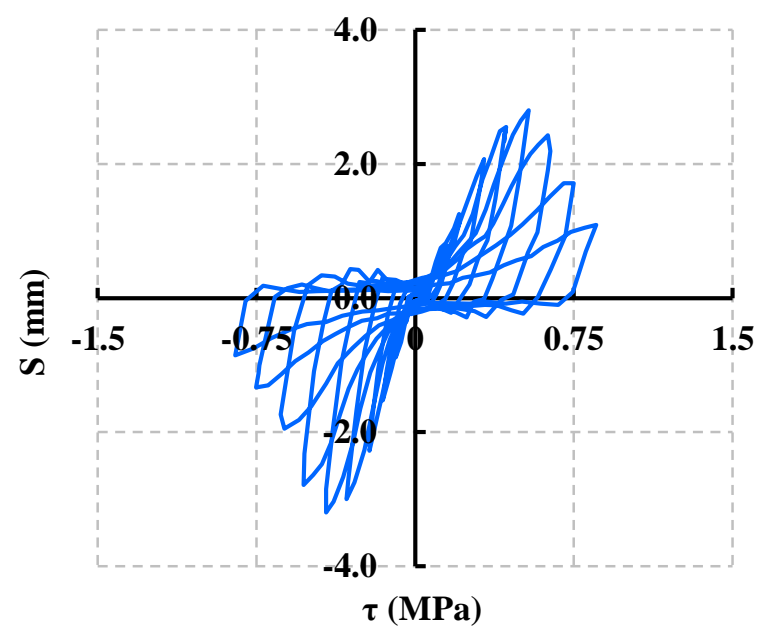

(d) F28d550Z-H

Fig. 11 Elastic-plastic hysteretic curves of the heated specimens with different curing ages. 


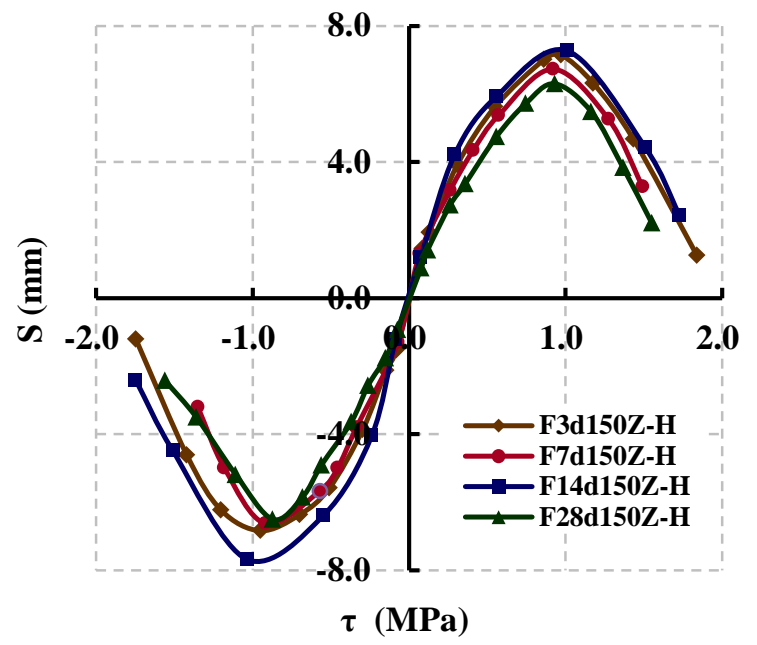

(a) $150^{\circ} \mathrm{C}$

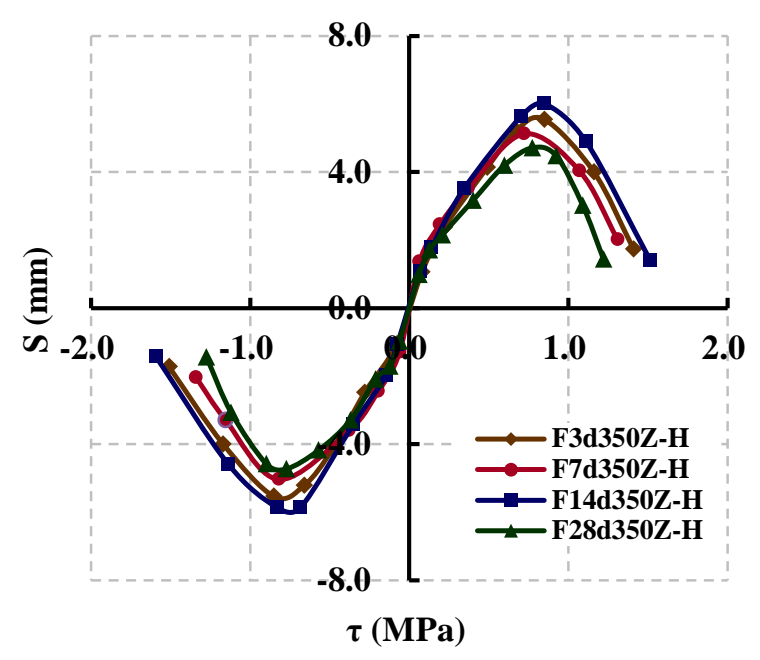

(b) $350^{\circ} \mathrm{C}$

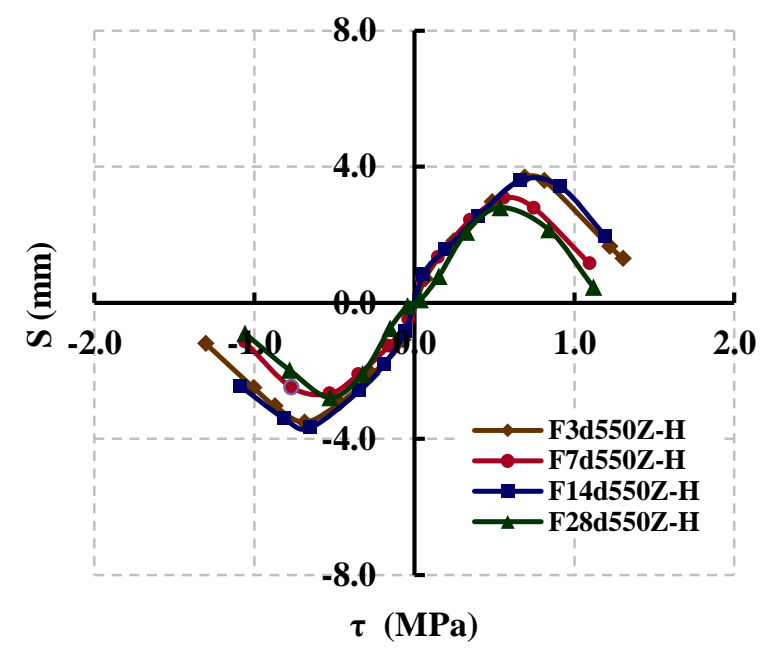

(c) $550^{\circ} \mathrm{C}$

Fig. 12 Envelope curves of the heated specimens with different curing ages. 


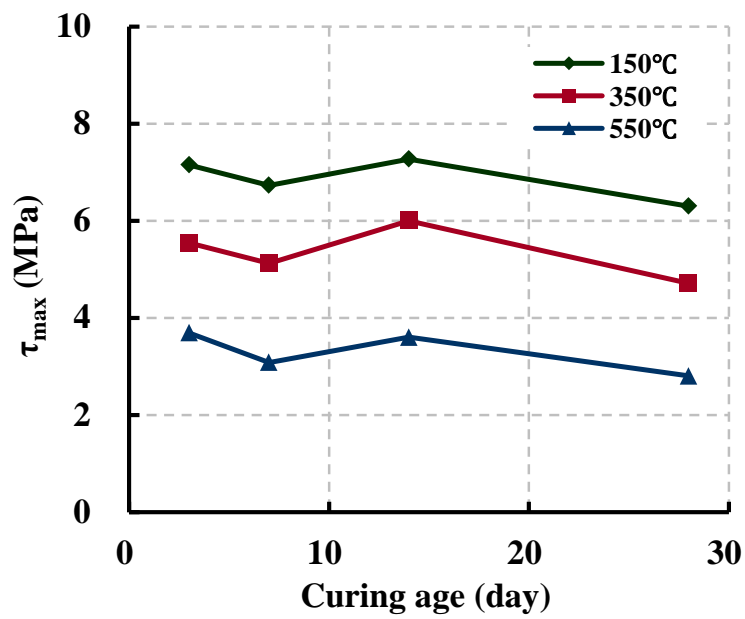

(a) Air cooling

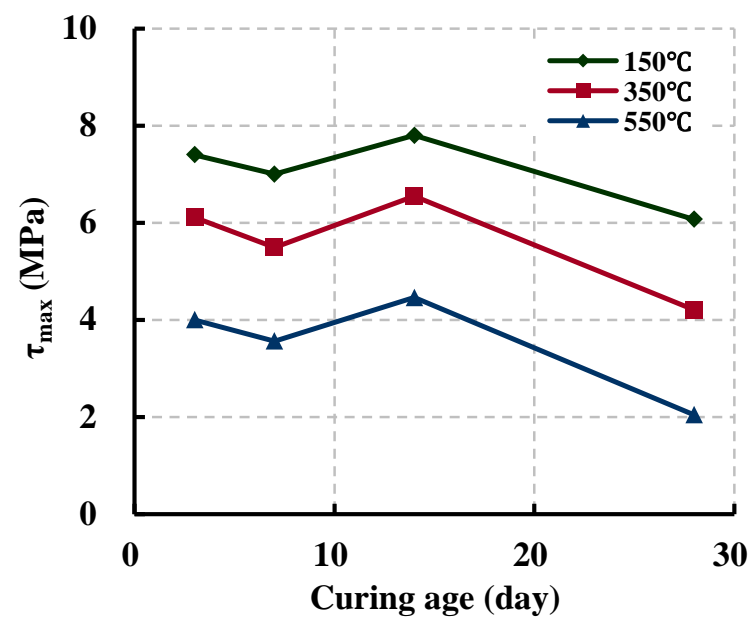

(b) Water cooling

Fig. 13 The ultimate bond stresses against curing ages for the specimens heated at high temperatures.

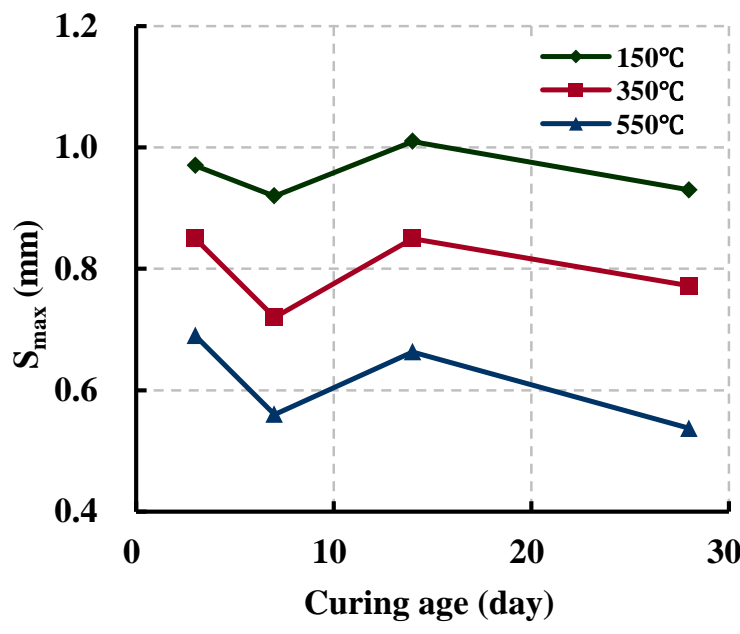

(a) Air cooling

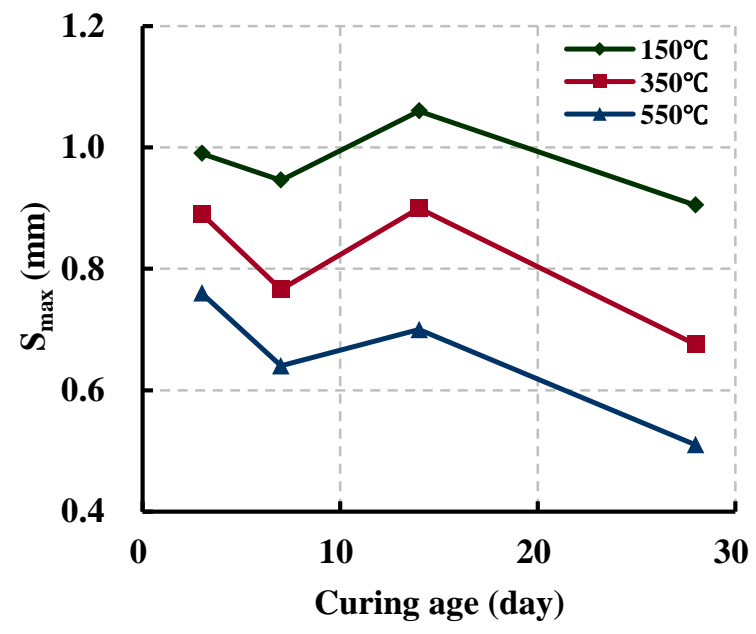

(b) Water cooling

Fig. 14 The ultimate bond slips against curing ages for the specimens heated at high temperatures. 


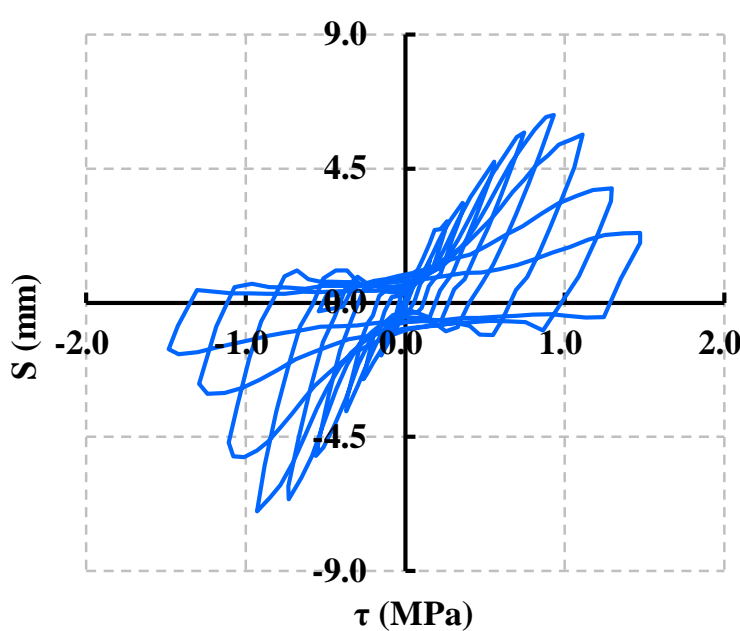

(a) F28d150Z-H (air cooling)

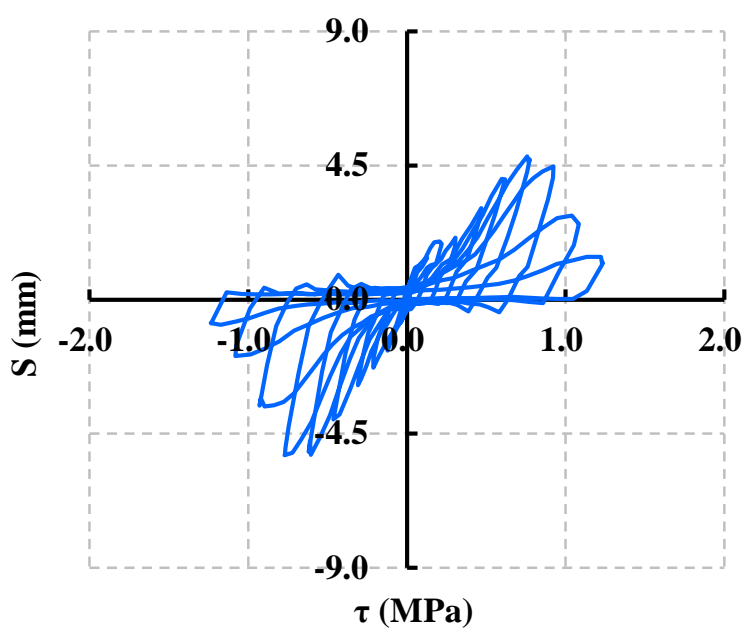

(c) F28d350Z-H (air cooling)

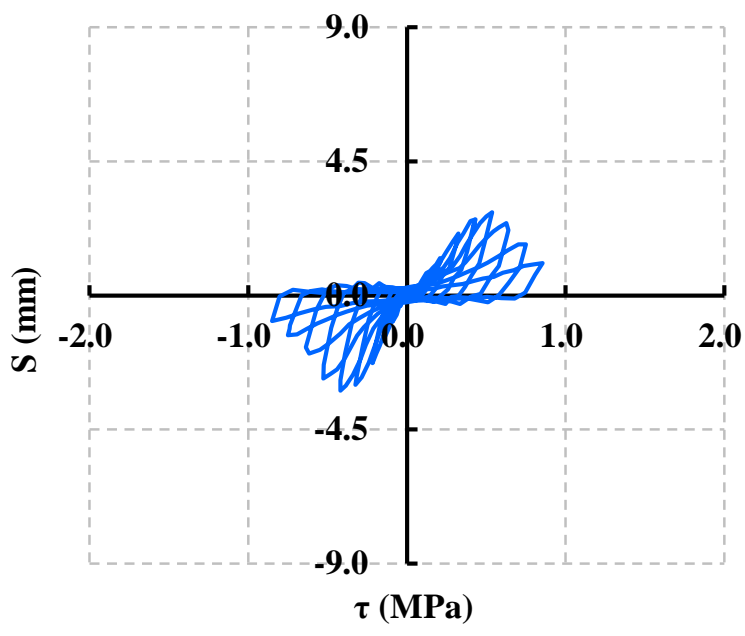

(e) F28d550Z-H (air cooling)

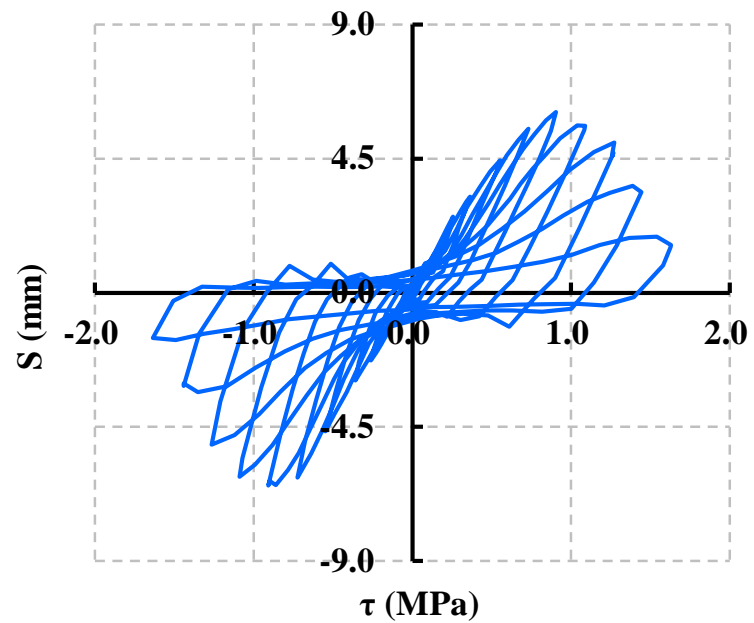

(b) F28d150S-H (water cooling)

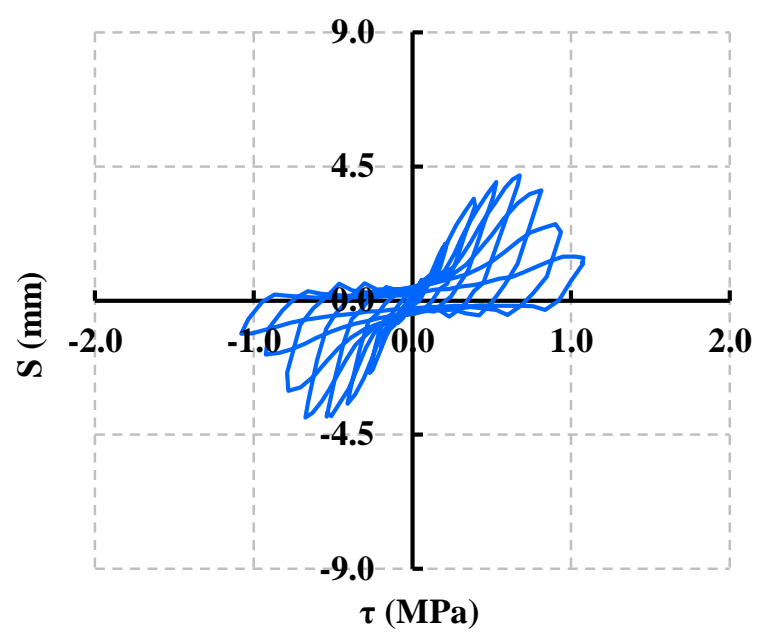

(d) F28d350S-H (water cooling)

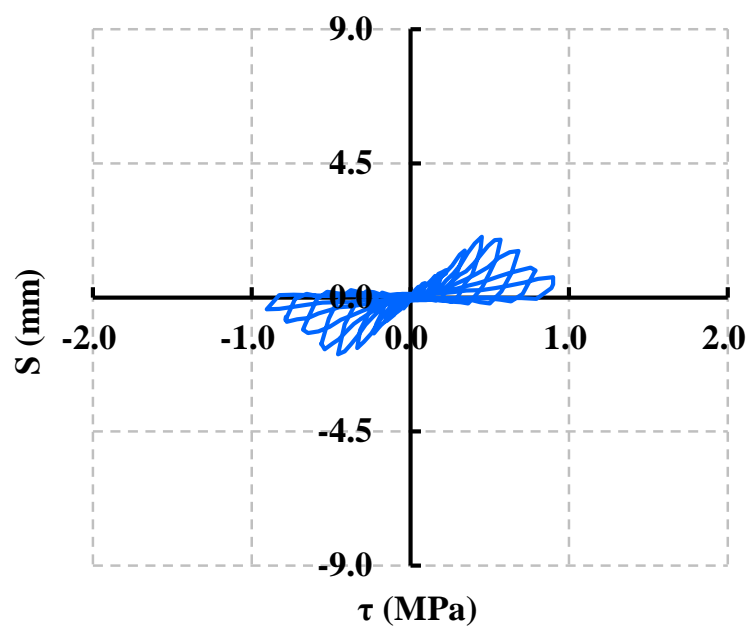

(f) F28d550S-H (water cooling)

Fig. 15 Elastic-plastic hysteretic curves of the heated specimens with the curing age of 28 days. 


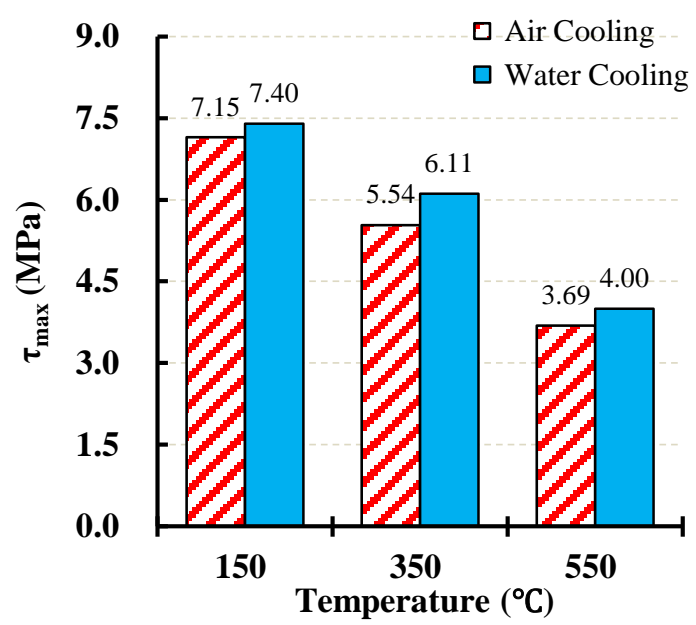

(a) 3 days curing age

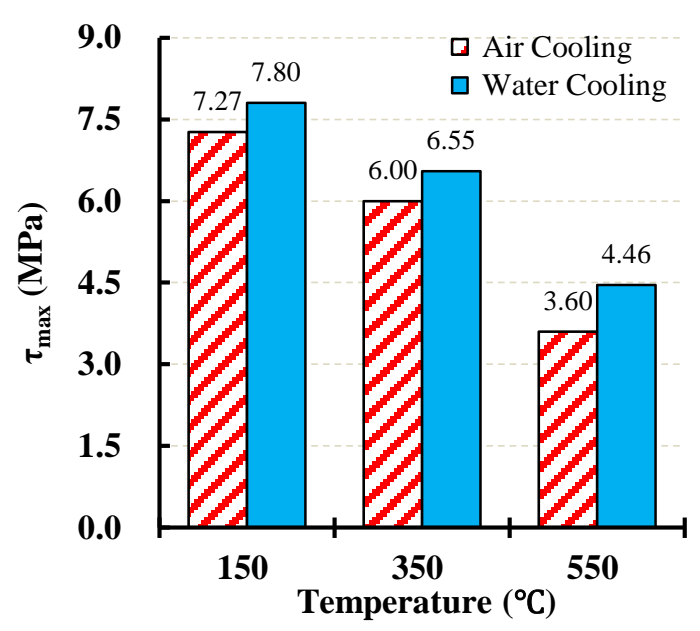

(c) 14 days curing age

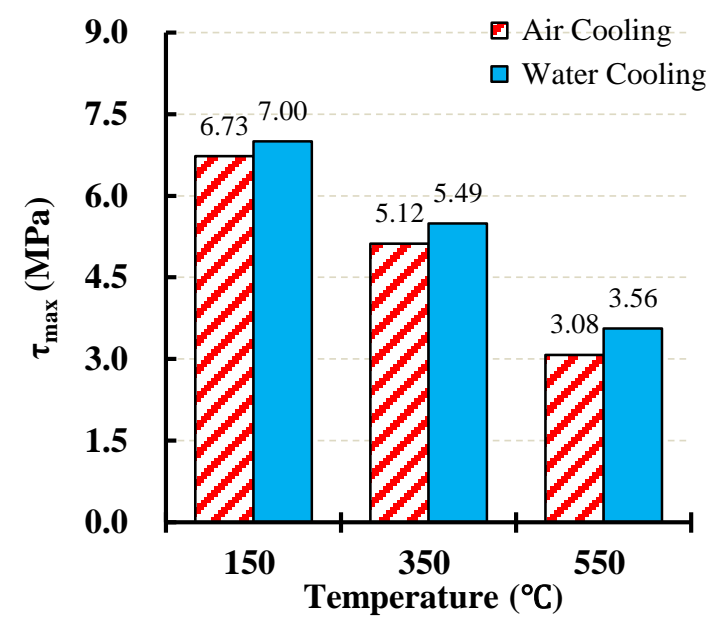

(b) 7 days curing age

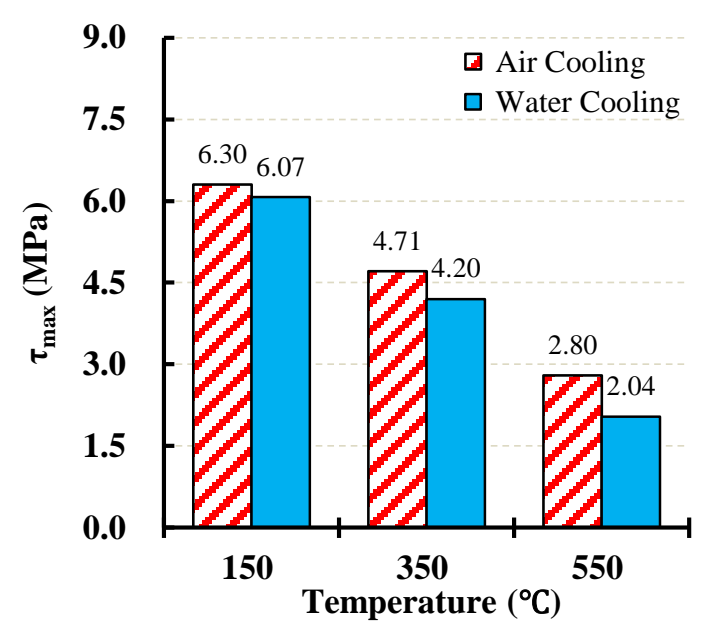

(d) 28 days curing age

Fig. 16 Influences of cooling methods on the ultimate bond stresses of the heated specimens. 


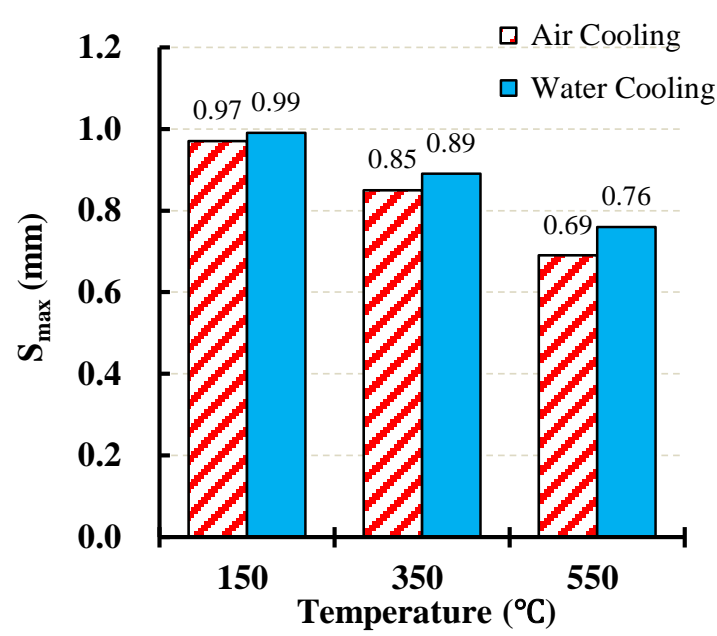

(a) 3 days curing age

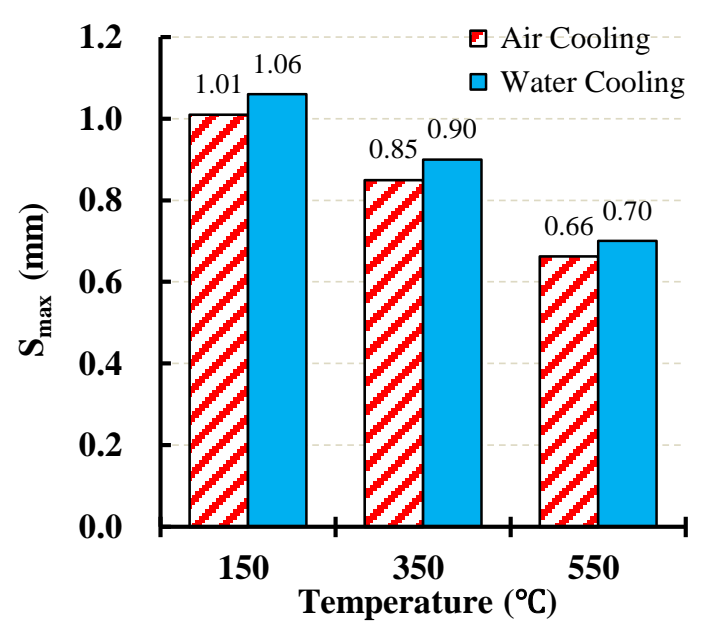

(c) 14 days curing age

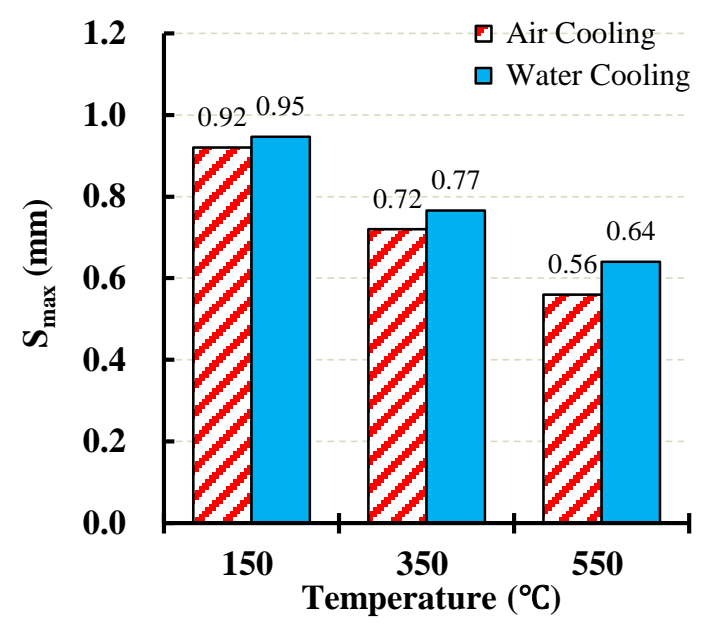

(b) 7 days curing age

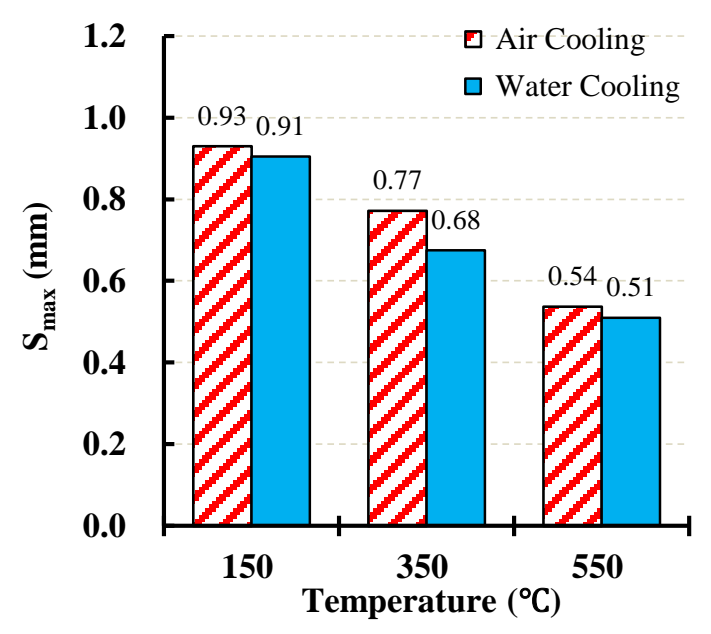

(d) 28 days curing age

Fig. 17 Influences of cooling methods on the ultimate bond slips of the heated specimens. 


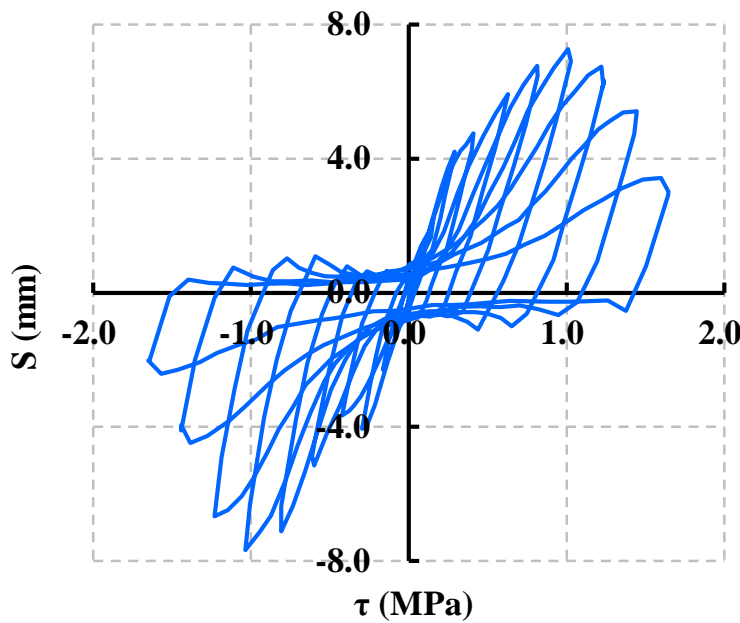

(a) F14d150Z-H

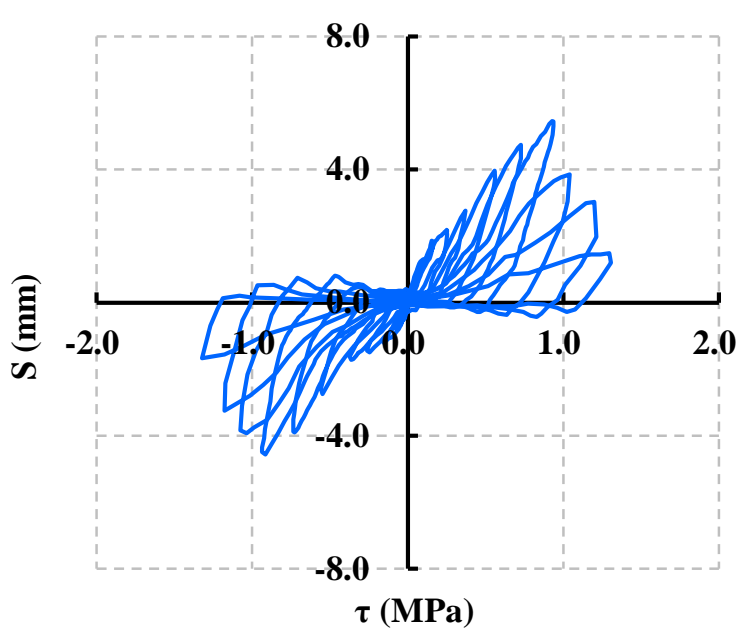

(c) $\mathrm{F} 14 \mathrm{~d} 350 \mathrm{Z}-\mathrm{H}$

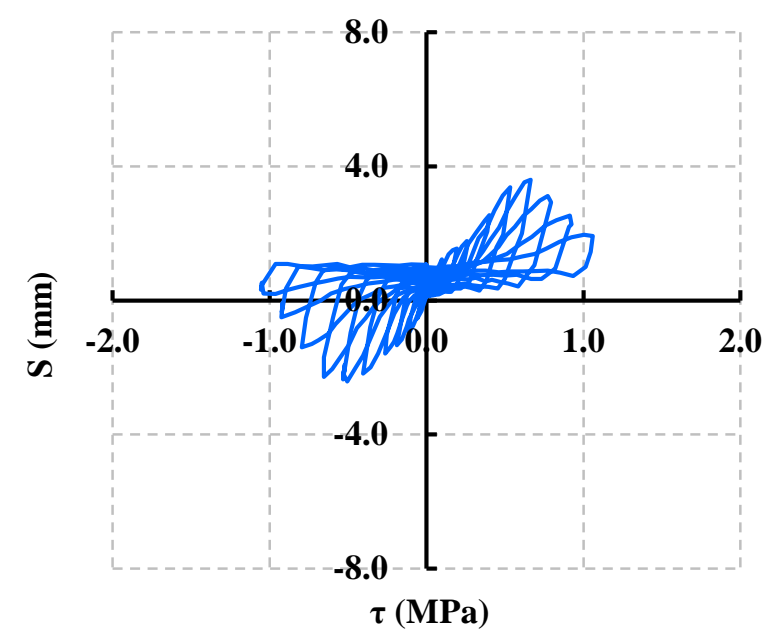

(e) F14d550Z-H

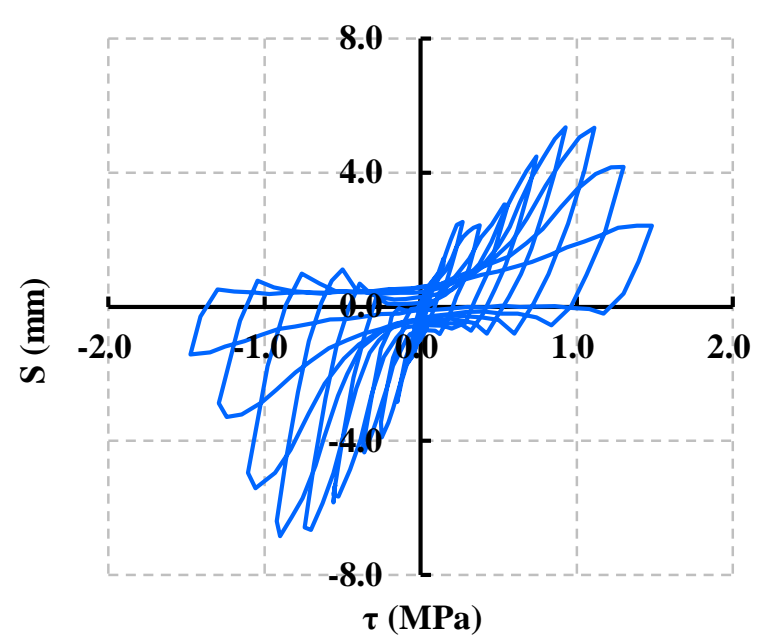

(b) F14d150Z

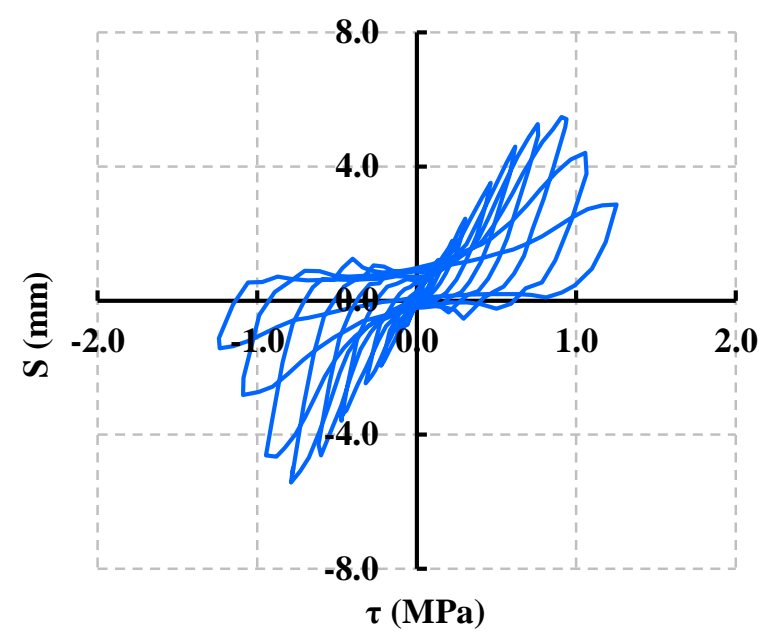

(d) F14d350Z

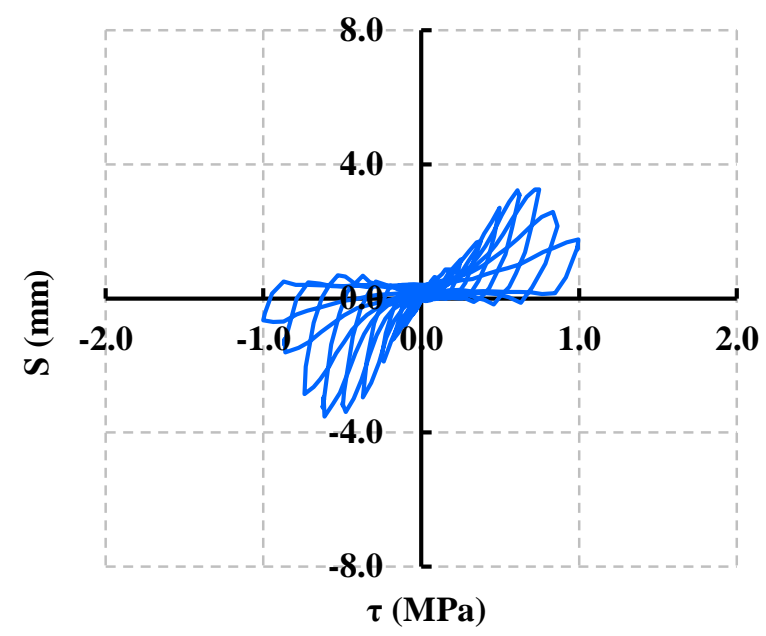

(f) $\mathrm{F} 14 \mathrm{~d} 550 \mathrm{Z}$

Fig. 18 Influences of stirrup on the elastic-plastic hysteretic curves of the specimens. 


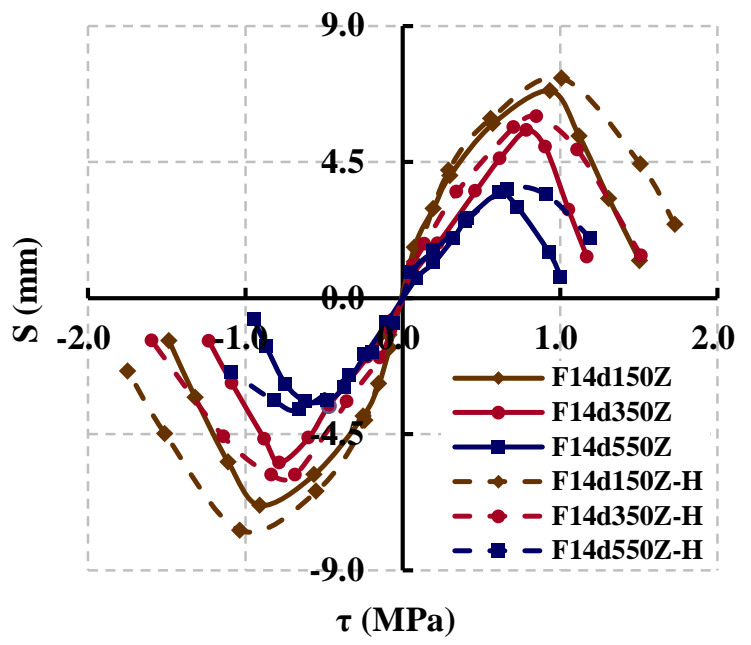

(a) Air cooling

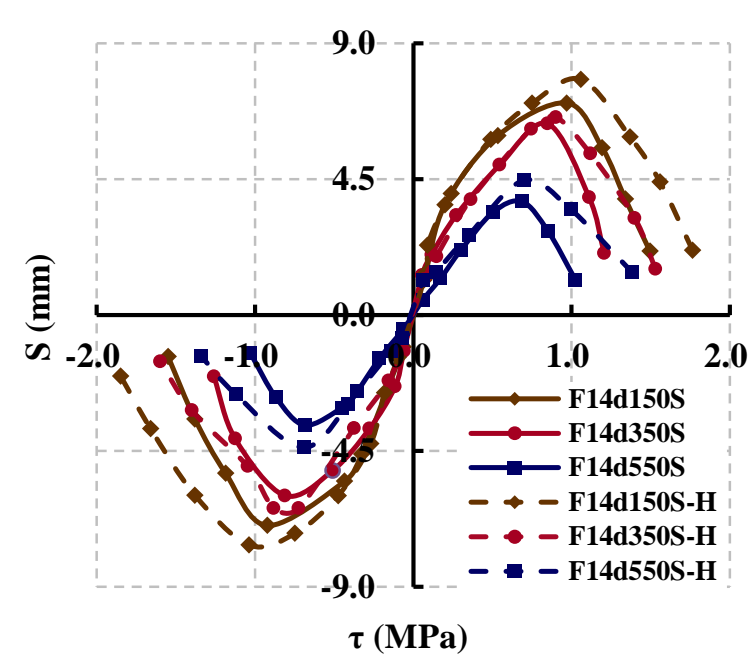

(b) Water cooling

Fig. 19 Influences of stirrup on the envelope curves of the specimens with 14 days curing age.

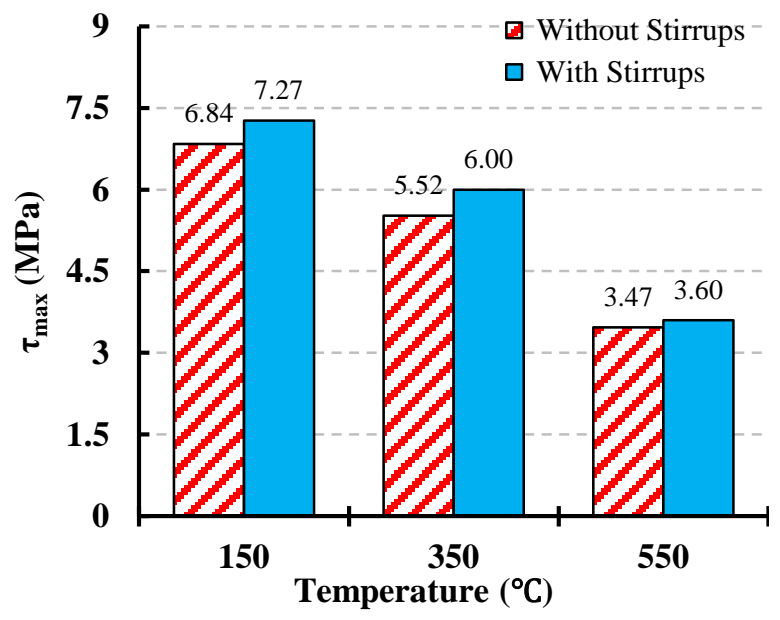

(a) Air cooling

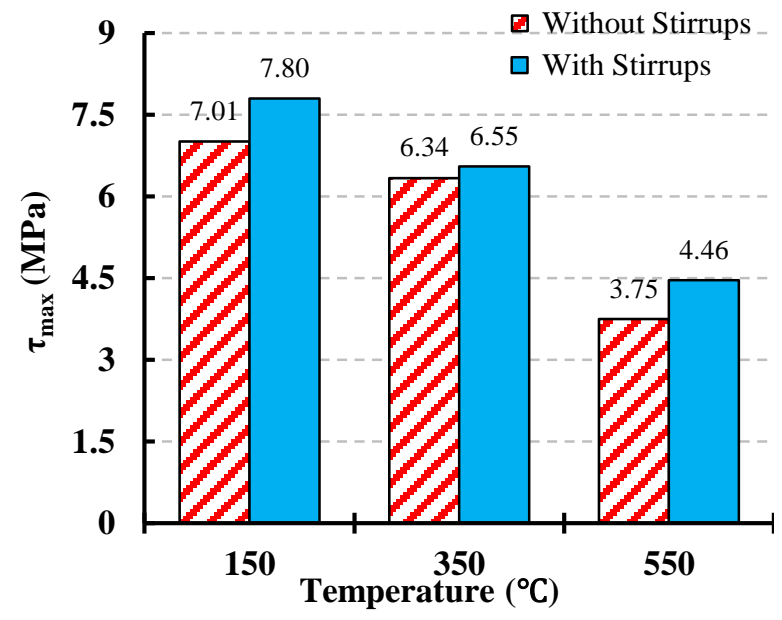

(b) Water cooling

Fig. 20 Influences of stirrup on the ultimate bond stresses of the heated specimens with 14 days curing age. 


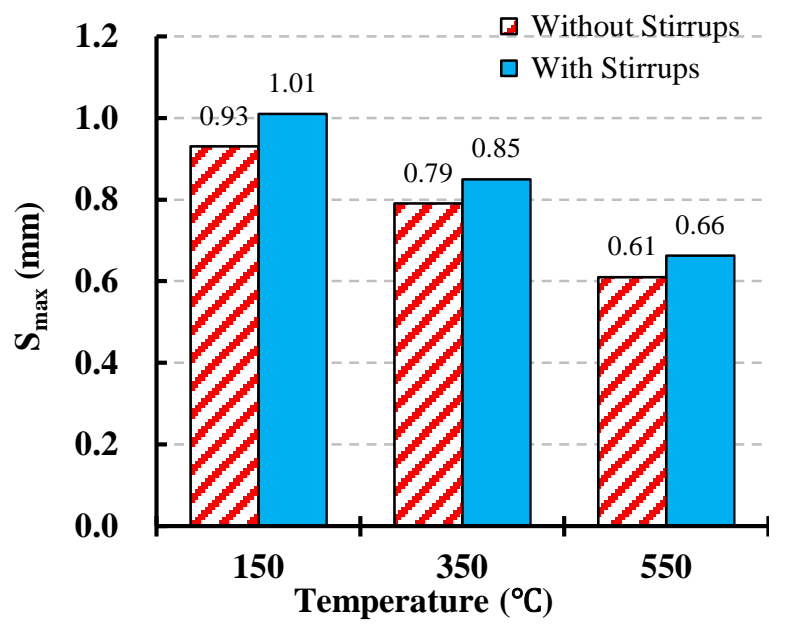

(a) Air cooling

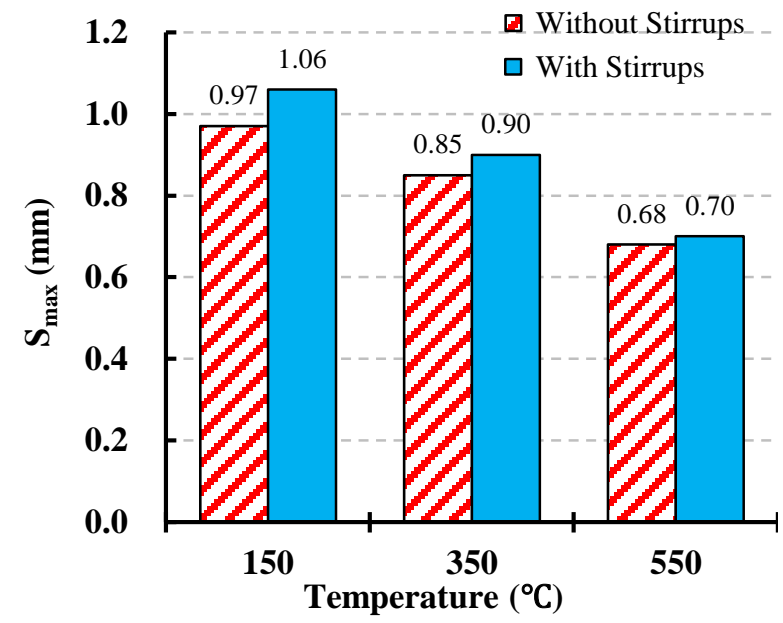

(b) Water cooling

Fig. 21 Influences of stirrup on the ultimate bond slips of the heated specimens with 14 days curing age. 